Chinese Journal of Organic Chemistry

\title{
不同环化方式下吡咯合成的研究进展
}

\author{
徐学涛 ${ }^{a}$ 陈 洁 ${ }^{a}$ 柯俊杰 ${ }^{a}$ 张 焜 ${ }^{a}$ 吴盼盼 ${ }^{*}, a$ 王少华 $*, b$ \\ ( ${ }^{a}$ 五邑大学生物科技与大健康学院 广东江门 529020) \\ $\left({ }^{b}\right.$ 兰州大学药学院 兰州 730000)
}

\begin{abstract}
摘要 吡咯作为一种重要的杂环, 广泛存在于天然产物、人造活性成分和功能材料等各种功能分子中. 这一事实促进 了这种结构单元合成方法学的发展. 总结了近五年来不同环化方式下吡咯合成的研究进展.
\end{abstract}

关键词 吡咯; 环化方式; 合成; 研究进展

\section{Recent Advances on Pyrrole Synthesis through Different Annulation Modes}

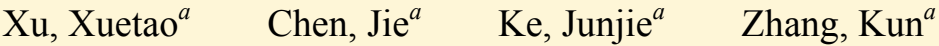 \\ Wu, Panpan*,a Wang, Shaohua*,b \\ ( ${ }^{a}$ School of Biotechnology and Health Sciences, Wuyi University, Jiangmen, Guangdong 529020) \\ $\left({ }^{b}\right.$ School of Pharmacy, Lanzhou University, Lanzhou 730000)
}

\begin{abstract}
Pyrrole, as one of the most important heterocycles, broadly exists in various functional molecules ranging from biological contexts to natural products, man-made bioactive molecules and functional materials. Such a fact has prompted the methodology development toward the construction of such a structural unit. The recent advances on pyrrole synthesis are summarized based on different cyclization modes.
\end{abstract}

Keywords pyrrole; cyclization modes; synthesis; recent advance

Pyrrole, as a basic five-membered aromatic heterocycle, has been recognized as one of the most important heterocycles due to its extensive utilities. ${ }^{[1-4]}$ Since its first detection by Runge in 1834 and structural confirmation by von Bayer in the 1870 s, pyrrole has been found not only in a variety of biological contexts, but also in lots of natural products, man-made bioactive molecules and functional materials. ${ }^{[5-10]}$ First of all, it is the basic component of a series of porphyrin-derived pigments, like chlorophylls, hemes and coenzyme F430, which are vital for nearly all organisms (Figure 1).

Meanwhile, this heterocycle is also the key skeleton moiety in many natural products mainly isolated from marine organisms, fungi, and bacteria exhibiting various biological activities. Some selected examples are shown in Figure 2, such as lamellarin type ${ }^{[11]}$ of natural products and $(+)$-roseophilin ${ }^{[12]}$ with good anticancer activities, curvulamine $^{[13]}$ with Gram-positive and -negative antibiotic activity, and synthetic challenging pyrrole-imidazole alkaloid palau'amine ${ }^{[14]}$ and massadine ${ }^{[15]}$ showing significant immune suppressive activity and antifungal activity (Figure 2).

In the past several years, there were still a number of natural products containing a pyrrole being isolated by phytochemists, and some selected examples are listed in Figure 3. Among them, 15'-oxoadenosceptrin and decarboxyagelamadin $\mathrm{C}$, two special hybrid pyrrole-imidazole alkaloids from the tropical sponge Agelass ceptrum, were reported by Muñoz and Köck in 2016. ${ }^{[16]}$ In 2016, Tan and co-workers isolated a unique indolizine alkaloid curindolizine with potent anti-inflammatory action through fungal cultivation. ${ }^{[17]}$ Sinopyrines $B-C$, two new pyrrole-bearing natural products from the family Menisper-

\footnotetext{
* Corresponding authors. E-mail: wyuchemwpp@126.com; wangshh@lzu.edu.cn Received May 8, 2020; revised July 15, 2020; published online July 30, 2020.

Project supported by the National Natural Science Foundation of China (Nos. 21472077, 21772071), the Fundamental Research Funds for the Central Universities (No. lzujbky-2018-134) and the Department of Education of Guangdong Province (Nos. 2017KTSCX185, 2017KSYS010, 2020KCXTD036, 2019KZDXM035).

国家自然科学基金(Nos. 21472077, 21772071)、中央高校基本科研基金(No. 1zujbky-2018-134)及广东省教育厅(Nos. 2017KTSCX185, 2017KSYS010, 2020KCXTD036, 2019KZDXM035)资助项目.
} 

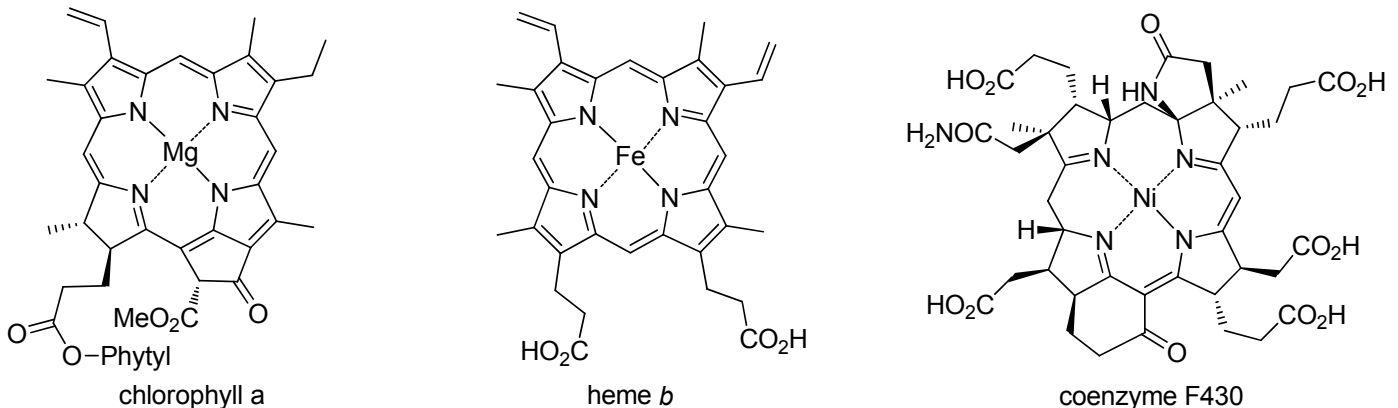

Figure 1 Structures of chlorophylls, hemes and coenzyme F430<smiles>COC(=O)c1c(-c2ccc(O)cc2)c(-c2ccc(O)cc2)cn1CC(=O)c1ccc(OC)cc1</smiles>

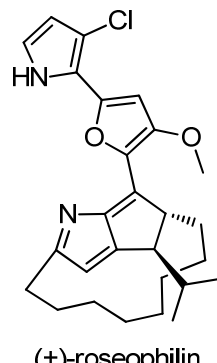
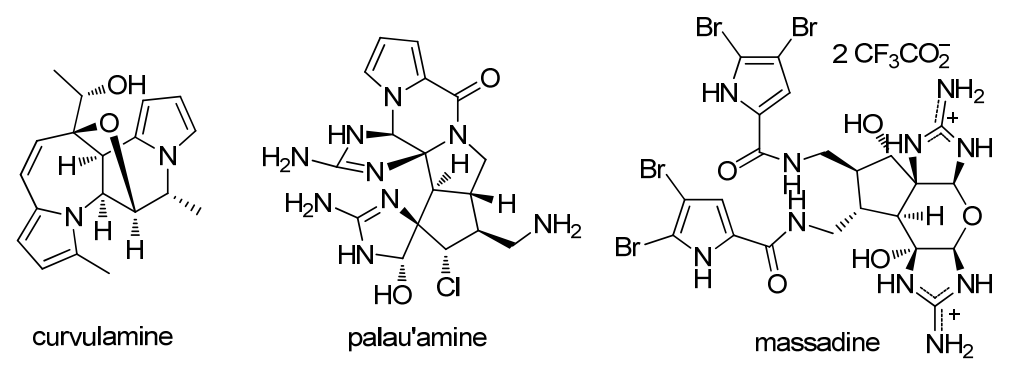

Figure 2 Selected bioactive natural products with pyrrole skeleton<smiles></smiles>

15'-oxoadenosceptrin<smiles>NCCC(=O)c1cccc2c1NC(CNC(=O)c1cc(Br)c(Br)[nH]1)C(c1cnc(N)[nH]1)O2</smiles>

decarboxyagelamadin C

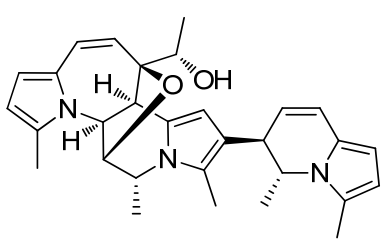

curindolizine<smiles>O=Cc1cccn1CCc1ccc(O)cc1</smiles>

sinopyrines $C$

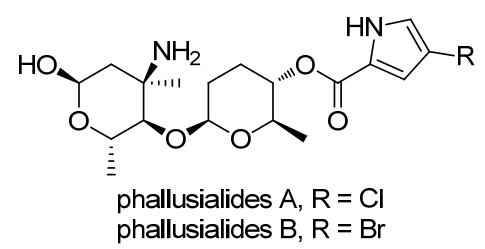<smiles>COc1cc2c(cc1O)-c1ccc(C=O)n1CCC2</smiles>

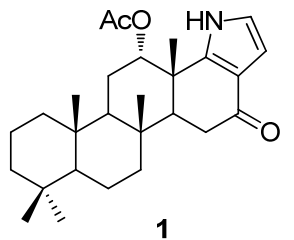

Figure 3 Some representative natural products isolated during the past five years

maceae, were isolated by $\mathrm{Tu}$ and co-workers ${ }^{[18]}$ from the stems and rhizomes of Sinomenium acutum (Thumb.) Rehd. et Wils. Phallusialides A and B, two new pyrrole-derived alkaloids showing antibacterial activity against methicillin resistant $S$. aureus and $E$. coli, has been isolated by Bugni and co-workers ${ }^{[19]}$ from a marinederived Micromonospora sp. Bacterium. Compound 1, a novel pyrrole-containing scalarane sesterterpenoid with cytotoxicity against six human cancer cell lines, has also been isolated by Lee et al. ${ }^{[20]}$ from the Scalarispongia sponge extract in 2019.

The ubiquity and corresponding activities of pyrrole alkaloids also stimulate the use of pyrrole as one of the most prevalent and privileged structural motifs for new functional molecule design leading to the development of various clinic drugs like Liptor for the treatment of high cholesterol, nonsquamous non-small cell lung cancer medicine Alimta, anti-inflammatory drug Tolmetin and anticancer drug Sutent (Figure 4). 
<smiles>CCCC(NC(=O)c1ccc(CCc2c[nH]c3[nH]c(N)nc(=O)c23)cc1)C(=O)N[C@@H](CO)CCCC(=O)O</smiles><smiles>CCN(CC)CCNC(=O)c1c(C)[nH]c(/C=C2\C(=O)Nc3ccc(F)cc32)c1C</smiles>

Figure 4 Selected pyrrole containing clinic drugs

The significant importance of pyrrole has also been prompting chemists' continuous efforts to develop synthetic methodologies toward the construction of such a structural unit. Although there have been some review articles concerning the synthesis of pyrrole and its derivatives, ${ }^{[21-22]}$ and numerous novel synthetic methods have been reported in the past five years. It is still necessary to summarize the recent progress of pyrrole construction for further advancement of such a research field and the discovery of new functional molecules. Generally, pyrrole is constructed through different cyclization modes, which can be simply divided into five categories, i.e., annulation of C4N1 unit, $[4+1],[3+2],[3+1+1]$ and $[2+2+1]$. Accordingly, the recent progresses of pyrrole synthesis based on above cyclization modes will be summarized.

\section{Annulation of C4N1 unit}

The annulation of C4N1 unit is one of the most direct ways for pyrrole synthesis. Generally, since all the five atoms required for constructing the five-membered ring have been included in the substrates, most of methods are focusing on the convenient introduction of substituents that are either important for corresponding functional molecules or readily for subsequent derivatization.

\subsection{Ring isomerization}

Isoxazole is a heterocycle that has been widely used to construct pyrrole ring due to its special isomerization property. In 2017, Khlebnikov and co-workers ${ }^{[23]}$ reported the first synthesis of pyrroles by isomerization of 4-vinylisoxazoles under mild reaction conditions with cheap and available $\mathrm{FeCl}_{2} \bullet 4 \mathrm{H}_{2} \mathrm{O}$ as a catalyst in high yields (Scheme 1). Under the activation of $\mathrm{Fe}$ catalyst, ring opening of substrate would give a Fe-nitrene complex, which could go through a 1,5-cyclization/isomerization to afford the pyrrole product.

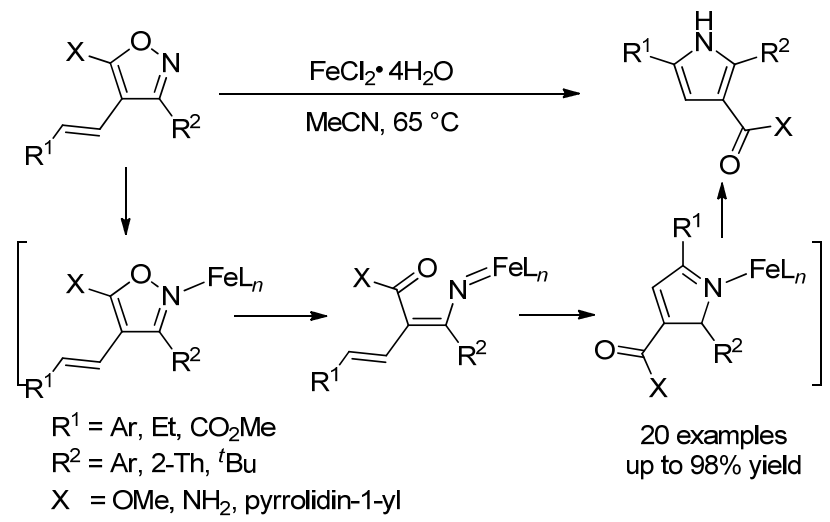

Scheme 1 Fe(II)-catalyzed ring isomerization

3,6-Dihydro-1,2-oxazines are another kind of heterocycles used for the synthesis of pyrrole through ring contraction. Aiming to the development of a more environment friendly strategy, Sawama group ${ }^{[24]}$ reported an efficient and direct synthesis of pyrroles using 3,6-dihydro-1,2oxazines and a reusable heterogeneous copper on carbon catalyst under neat heating conditions (Scheme 2). An one-pot manner from nitroso dienophiles and 1,3-dienes was also successful under the same conditions.

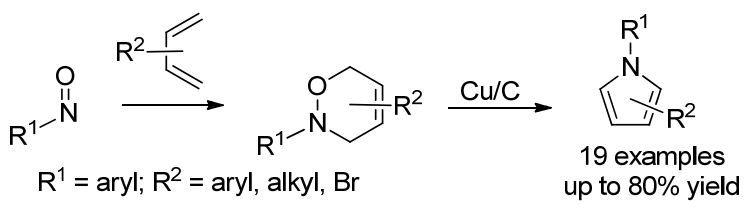

Scheme 2 Ring contraction of 3,6-dihydro-1,2-oxazines

\subsection{Direct cyclization}

Homopropargyl amine is one of the most common substrates for the pyrrole synthesis via direct cyclization. Therefore, the current focus of such a strategy is how to enhance the transformation efficiency during corresponding cyclization. The introduction of an amido group during such a ring formation process was realized by Reddy group ${ }^{[25]}$ through a tandem heteropalladation/isocyanate insertion cascade affording substituted furan/pyrrole-3-carboxamides (Scheme 3).

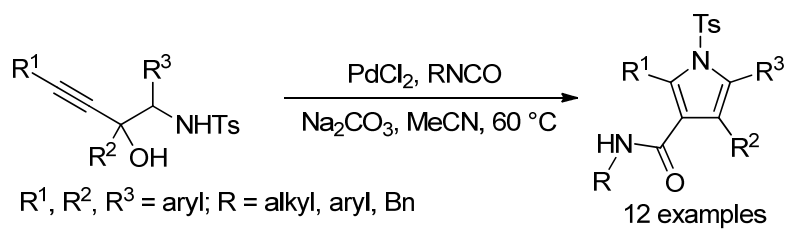

Scheme $3 \quad \mathrm{PdCl}_{2}$ mediated tandem heteropalladation/isocyanate insertion reaction

In 2018, Yan and co-workers ${ }^{[26]}$ developed a metal-free reaction to synthesize substituted sulfonylpyrroles from the homopropargyl amines and sulfinic acids via tandem addition/cyclization in moderate to good yields, in which tert-butyl nitrite $(\mathrm{TBN})$ was employed as the oxidant for the installation of the sulfonyl group (Scheme 4). 


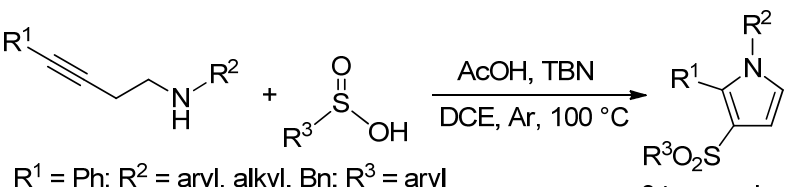

$$
\begin{aligned}
& \mathrm{R}^{1}=\mathrm{Ph} ; \mathrm{R}^{2}=\text { aryl, alkyl, Bn; } \mathrm{R}^{3}=\text { aryl } \quad 34 \text { examples } \\
& \text { up to } 90 \% \text { yield }
\end{aligned}
$$

Scheme 4 Cyclization of homopropargylamines and sulfinic acids

Inspired by the transformations of hydroxylamine derivatives via the cleavage of $\mathrm{N}-\mathrm{O}$ bond, Shen et al. ${ }^{[27]}$ reported an iridium catalyzed fragmentation/cyclization of $\mathrm{N}$-butynyl 4,4-dimethylisoxazolidine-3,5-diones providing substituted $N$-isobutyrylpyrroles (Scheme 5).
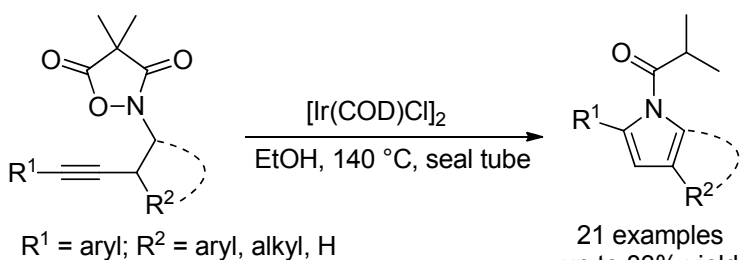

21 examples up to $83 \%$ yield

Scheme 5 Iridium-catalyzed fragmentation/cyclization cascade

In 2019, using enyne sulfonamides as substrates, Chen, Zhu and co-workers ${ }^{[28]}$ achieved a direct synthesis of fully substituted formyl pyrrole derivatives under the catalysis of

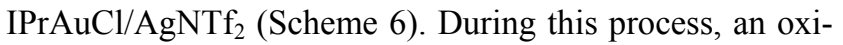
dation of 3-methylene dihydropyrrole intermediate to azafulvenium intermediate was proposed as the key step for the formation of the final products.

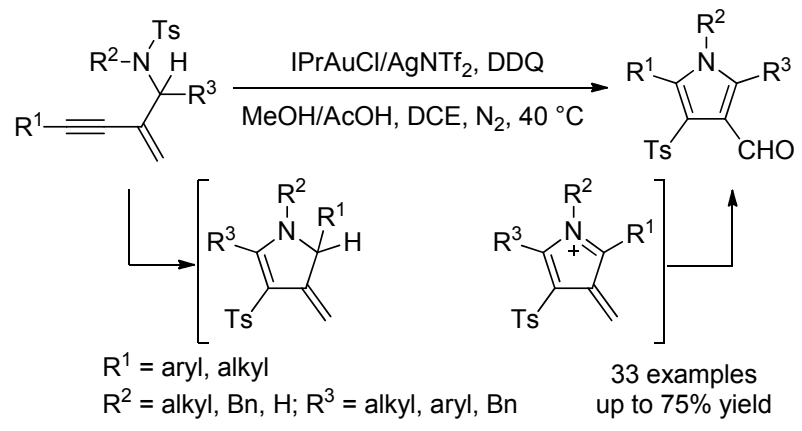

Scheme 6 Au-catalyzed cyclization of enyne sulfonamides
Other than homopropargyl amine, propargyl amine is another type of substrate that has been used in this reaction mode, although it requires a suitable substituent on the nitrogen atom. In the case of the substituent being a substituted vinyl moiety, an Au-catalyzed propargyl-Claisen rearrangement/cyclization reaction of $N$-propargyl- $N$-vinyl sulphonamides prepared by a base-mediated formal vinylic substitution reaction of 2-bromoallyl sulfones was developed by Menon and co-workers ${ }^{[29]}$ affording a series substituted pyrroles (Scheme 7). Moreover, the selectivity of the cyclization pathway could be controlled by the catalyst, and dihydropyridine products were obtained by using the combination of $\mathrm{Ph}_{3} \mathrm{PAuCl}$ and $\mathrm{AgSbF}_{6}$.

Using similar type of substrates, Wan and Xin et al. ${ }^{[30]}$ achieved the selective synthesis of 2-trifluoromethyl5-(arylsulfonyl)methyl pyrroles and 2-trifluoromethyl4-(arylsulfonyl)methyl pyrroles from trifluoromethylsubstituted 3-aza-1,5-enynes via a cyclization/sulfonylmigration cascade using $\mathrm{AgOOCCF}_{3}$ and $\mathrm{CsOPiv}$ as catalyst, respectively (Scheme 8). Additionally, alkylvinylsubstituted pyrroles could be obtained from the substrates with an ester group at the position of $\mathrm{CF}_{3}$ group through aryl sulfinic acid elimination under the promotion of $\mathrm{Cs}_{2} \mathrm{CO}_{3}$.

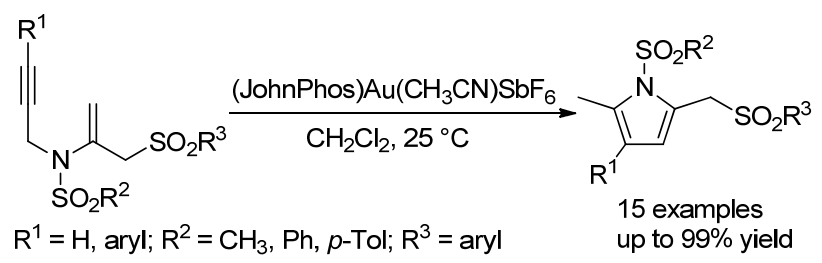

Scheme 7 Au-promoted cyclization of $N$-propargyl- $N$-vinyl sulphonamides

$N$-propargylic $\beta$-enaminones are another kind of substrates applied to the pyrrole construction. In 2016, a strategy using $N$-alkyl, $N$-propargylic $\beta$-enaminones as substrates has been developed by Zhang and co-workers ${ }^{[31]}$ for the synthesis of tetrasubstituted pyrroles in moderate to good yields under the promotion of ${ }^{t} \mathrm{BuOK}$ (Scheme 9).

Interestingly, a simple replacement of the alkyl group on nitrogen atom with hydrogen would lead to different results. Using $\mathrm{KOH}$ as the promoter, Cui and co-workers ${ }^{[32]}$ observed the formation of polysubstituted $N$-(2-pyridyl)-

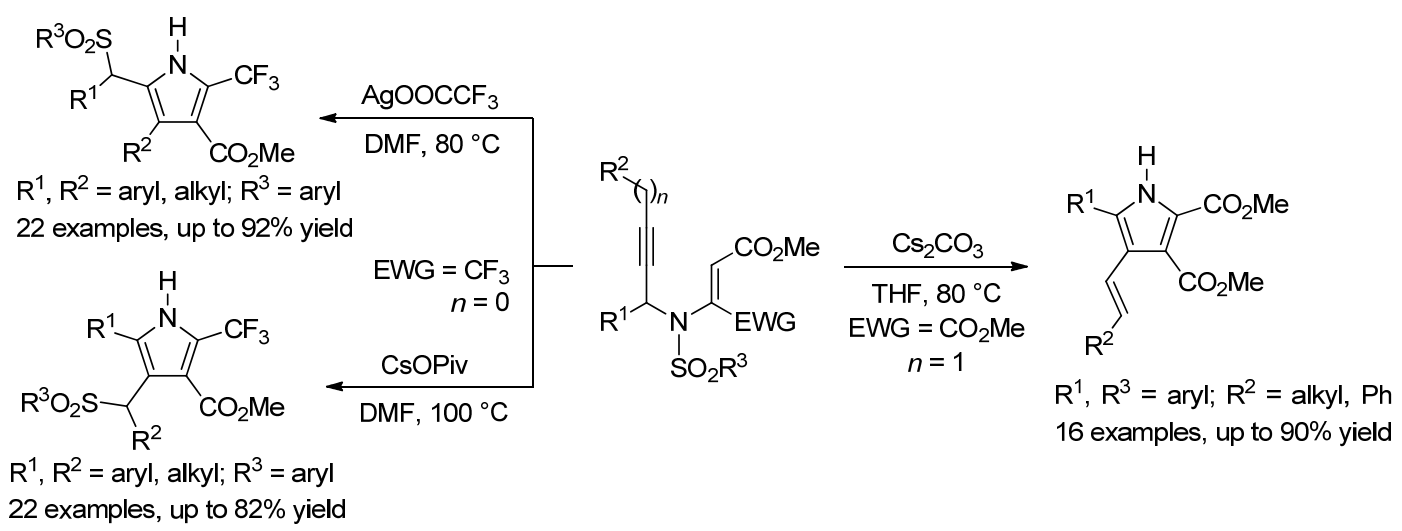

Scheme 8 Silver or cesium catalyzed reaction of trifluoromethyl-substituted 3-aza-1,5-enynes 


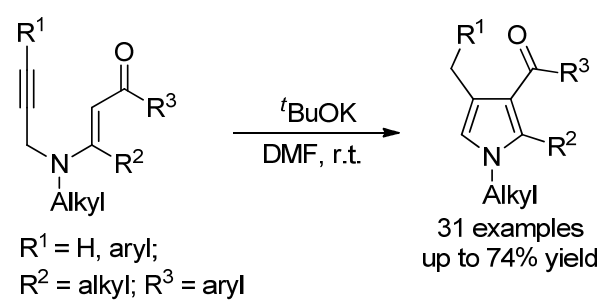

Scheme $9{ }^{t} \mathrm{BuOK}$-promoted annulation of $N$-propargylic $\beta$ enaminones

pyrroles, which were formed by the coupling of two in situ generated intermediates (Scheme 10).

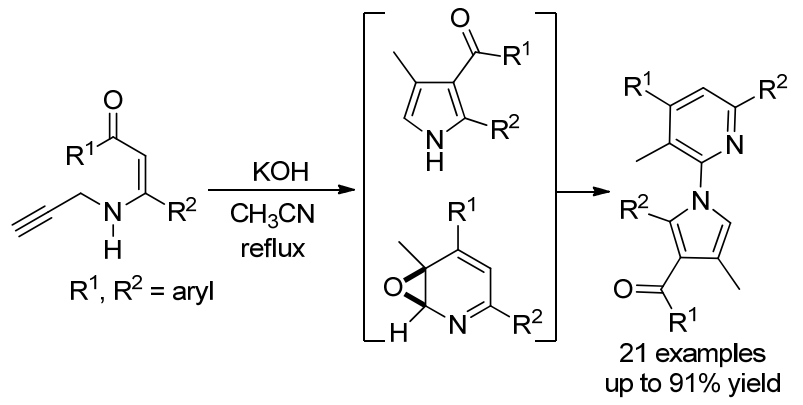

Scheme $10 \mathrm{KOH}$-catalyzed cyclization of $N$-propargylic $\beta$ enaminones

In contrast, if ${ }^{t} \mathrm{BuOK}$ was used as the promoter, a selective cleavage of a $\mathrm{C}(\mathrm{CO})-\mathrm{C}\left(\mathrm{sp}^{2}\right)$ bond would occur during the cyclization reaction of $N$-propargyl $\beta$-enaminones, which could give 2,3,4-trisubstituted pyrroles in moderate to good yields (Scheme 11). ${ }^{[33]}$

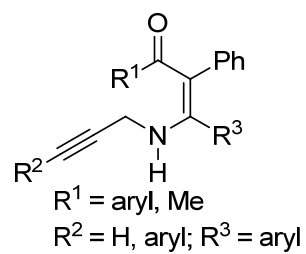

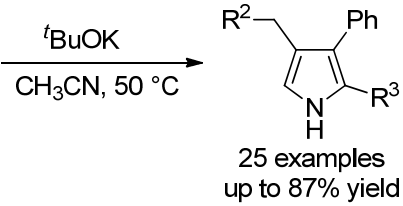

Scheme $11{ }^{t} \mathrm{BuOK}$-mediated reaction of $N$-propargyl $\beta$-enaminones

In 2018, Lam's group ${ }^{[34]}$ also reported a nickel- catalyzed arylative cyclization of $N$-tosyl alkynamides affording multisubstituted pyrroles with good yields, and this method was applied for the formal synthesis of two borondipyrromethenes and a known inhibitor of bovine cyclooxygenase and 5-lipoxygenase (Scheme 12).

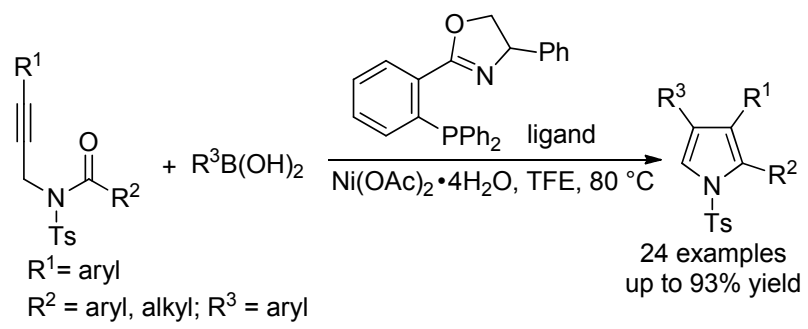

Scheme 12 Nickel-catalyzed cyclization of $N$-tosylalkyn-amide
Based on their systematic studies on ynamines, Ye and co-workers ${ }^{[35]}$ developed a gold-catalyzed tandem cyclization of $N$-propargyl ynamides leading to a series of indeno[1,2-c]pyrroles in 2018 (Scheme 13). During this reaction, a vinyl cation intermediate was proposed for the second cyclization.

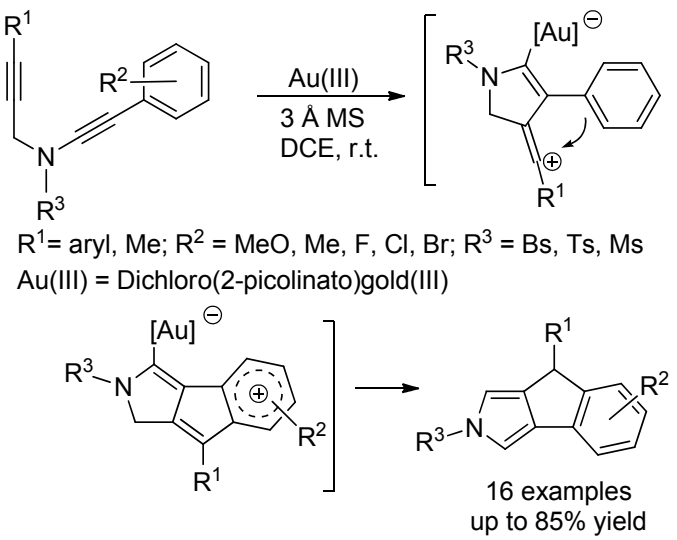

Scheme 13 Gold-catalyzed tandem cyclization reaction

In 2019, Liu and Dong et al. ${ }^{[36]}$ published an organocatalytic cycloisomerisation of $Z$-1-iodo-4- $N$-methylbenzenesulfonyl-1,6-enynes to functionalized pyrroles in the presence of ${ }^{t} \mathrm{BuOK}$. Based on some control experiments, a radical-type mechanism was proposed for this reaction (Scheme 14).

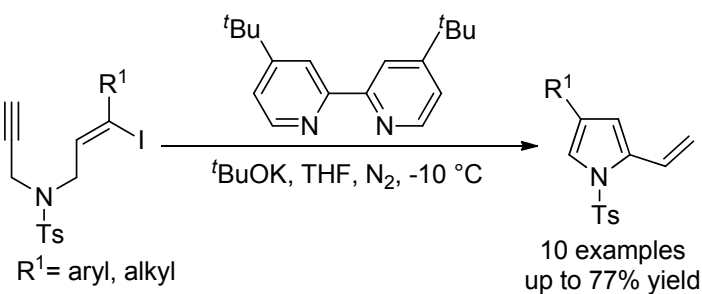

Scheme 14 Organocatalytic cycloisomerization of Z-1-iodo4- $N$-methylbenzenesulfonyl-1,6-enynes

Besides above amine type of substrates, 1-alkynyl oxime derivatives are also a kind of suitable starting materials for the pyrrole synthesis. In 2016, using 1-(1-alkynyl)cyclopropyl oximes as the substrates, Shi and co-workers ${ }^{[37]}$ disclosed a $\operatorname{Pd}(\mathrm{II})$-catalyzed tandem heterocyclization protocol for the synthesis of highly functionalized pyrroles (Scheme 15). Since an intermolecular nucleophilic attack is the key step for the pyrrole formation, diverse substituents could be introduced through the use of different nucleophiles.

$\alpha$-Diazo oxime ethers have been used for the construction of a series of multisubstituted pyrroles by $\mathrm{Xu}$ and co-workers ${ }^{[38]}$ affording products with good structural diversity (Scheme 16). Different from the work of Park, ${ }^{[39]}$ a novel cascade process was proposed because of the presence of alkynyl moiety in the substrates. 


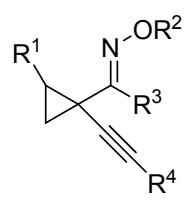

$\mathrm{NuH}=\mathrm{RCO}_{2} \mathrm{H}, \mathrm{ROH}, \mathrm{TsNHBoc}, \mathrm{CNCH}_{2} \mathrm{CO}_{2} \mathrm{Et}$ $\mathrm{R}^{1}=\mathrm{H}, \mathrm{Ph}$, alkyl; $\mathrm{R}^{3}=\mathrm{H}, \mathrm{Me}, \mathrm{Ph}$ $\mathrm{R}^{4}=$ aryl, Bn when $\mathrm{R}^{2}=\mathrm{H}, \mathrm{R}^{5}=\mathrm{H}, \mathrm{Ac}$ when $\mathrm{R}^{2}=\mathrm{Me}, \mathrm{R}^{5}=\mathrm{Me}$

Scheme 15 Palladium-promoted cyclization of 1-(1-alkynyl)cyclopropyl oximes<smiles>[R]C#CCOC(=O)C(=N[R]#[R])/C([R1])=N\OC</smiles>

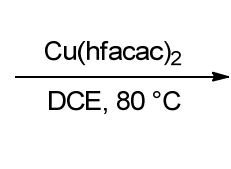<smiles></smiles>

Scheme 16 Copper-catalyzed cyclization of propargyl $\alpha$-iminodiazoacetates

Following their research interests in chemical property investigation of tertiary enamides, Wang, Tong and co-workers ${ }^{[40]}$ developed a practical method for the selective synthesis of pyrrole derivatives through an $\mathrm{AlCl}_{3}$ catalyzed cyclization/isomerization/dehydration aromatization cascade of tertiaryenamides (Scheme 17). Additionally, the selectivity of such a reaction could be switched by simply using $\mathrm{Sc}(\mathrm{OTf})_{3}$ to give vicinal amino alcohol derivatives.

$$
\begin{aligned}
& \mathrm{R}^{1}=\mathrm{H}, \text { alkyl; } \\
& \mathrm{R}^{2}, \mathrm{R}^{3}=\text { aryl, alkyl }
\end{aligned}
$$

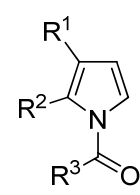

21 examples up to $99 \%$ yield
Scheme 17 Aluminum-promoted cyclization of tertiary enamides

It is also noteworthy that non-arene nitrodienes have been rarely used for the synthesis of pyrroles, despite the broad utility of their analogues in the construction of indole type of compound via the Cadogan-Sundberg approach. In 2017, Karimi et al. ${ }^{[41]}$ reported a Mo-catalyzed cyclization of non-arene nitrodienes affording substituted pyrroles in the presence of triphenylphosphine (Scheme 18). During this reaction process, a nitrene intermediate was proposed based on density functional theory (DFT) calculation.
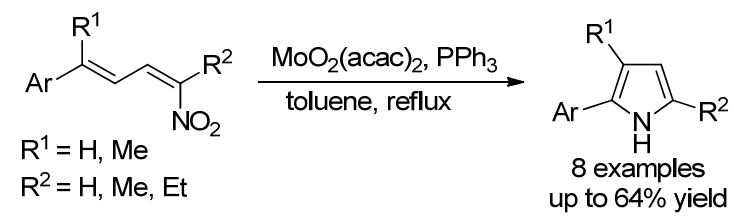

Scheme 18 Molybdenum-catalyzed annulation of nitrodienes

\section{$2[4+1]$ mode}

Formal $[4+1]$ reaction mode is another very common strategy for the construction of pyrrole ring, and normally divided into two categories, i.e., $\mathrm{N} 1$ and $\mathrm{C} 1$ unit participated cyclization modes, of which the first one is more frequently used.

\subsection{N1 unit participated mode}

In the case of N1 unit related methods, it can reach back to the classic Paal-Knorr cyclization. Nowadays, based on the same cyclization strategy, corresponding methodology development has been shifted to the in situ generation of 1,4-dicarbonyl intermediate and its surrogates.

Generally, oxidation of 1,4-diols represents one of the most direct way to obtain 1,4-dicarbonyl precursors. Compared with traditional oxidation conditions, catalytic dehydrogenation of alcohols represent a sustainable way for the synthesis of corresponding carbonyl compounds, and have been used for the construction of pyrrole ring by several research groups. In 2016, Milstein and co-workers ${ }^{[42]}$ developed a cobalt pincer complexes catalyzed coupling reactions of diols with amines via dehydrogenative coupling to prepare substituted pyrroles in good to excellent yields. And water and $\mathrm{H}_{2}$ are the only by-products during this reaction (Scheme 19).

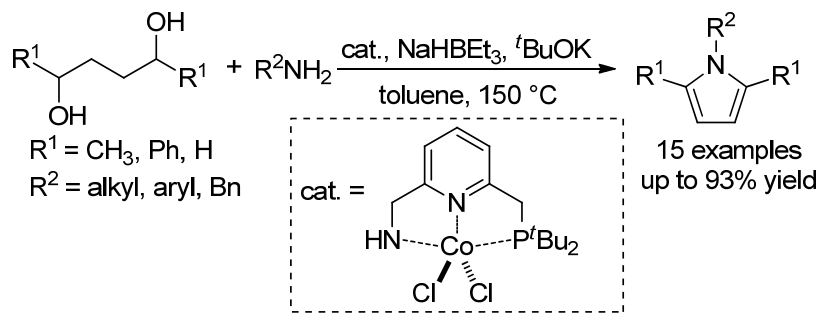

Scheme 19 Cobalt pincer complexes promoted synthesis of pyrroles

In 2018, using a sustainable nickel catalyst, Banerjee and co-workers $^{[43]}$ reported a direct synthesis of $N$-substituted pyrroles from 2-butene-1,4-diols or 2-butyne-1,4-diols with aryl- and alkylamines (Scheme 20).

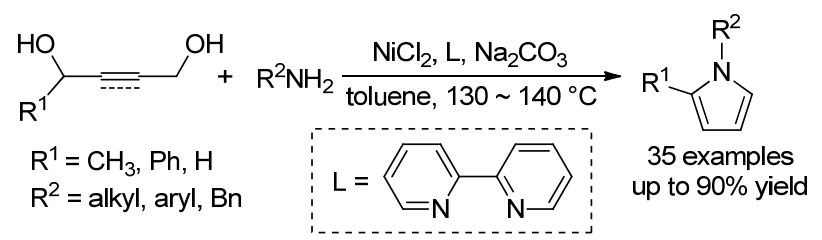

Scheme 20 Nickel-mediated pyrrole synthesis via a formal $[4+1]$ cyclization

Rearrangement reaction is another way to generate 1,4-carbonyl intermediates. In 2015, toward the construction of cyclopenta $[b]$ pyrrole moiety, a common skeleton of a series of bioactive molecules, Wang and co-workers ${ }^{[44]}$ developed an $\mathrm{Au}(\mathrm{I})$-catalyzed tandem reaction for the synthesis of tetrahydrocyclopenta[ $b]$ pyrroles, from which a potent anti-inflammatory agent was obtained (Scheme 21). 
During this process, a 1,4-dicarbonyl intermediate was formed through a Meyer-Schuster/semipinacol rearrangement cascade for the final cyclization. Leboeuf and co-workers $^{[45]}$ also described a one-pot reaction sequence to generate similar types of products using 2-furylcarbinols and anilines as substrates under the catalysis of $\mathrm{Ca}\left(\mathrm{NTf}_{2}\right)_{2}$ and $\mathrm{Cu}\left(\mathrm{OTf}_{2}\right)_{2}($ Scheme 22).

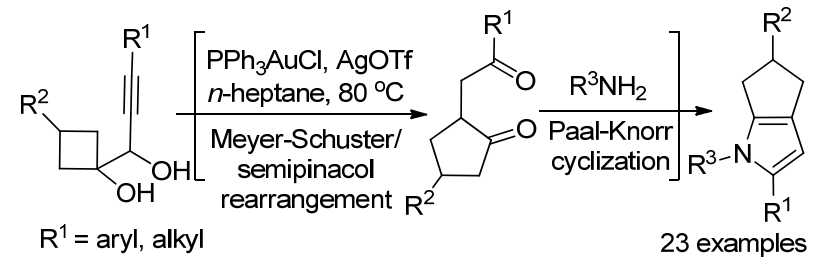

$\mathrm{R}^{2}=\mathrm{H}, \mathrm{Ph} ; \mathrm{R}=$ aryl, alkyl, Bn, propargyl 23 examples
up to $65 \%$ yield

Scheme 21 Au-catalyzed rearrangement/cyclization cascade<smiles>[R][X]1cc([R]#Cc2coc(C([R])([R])O)c2)ccc1N</smiles>

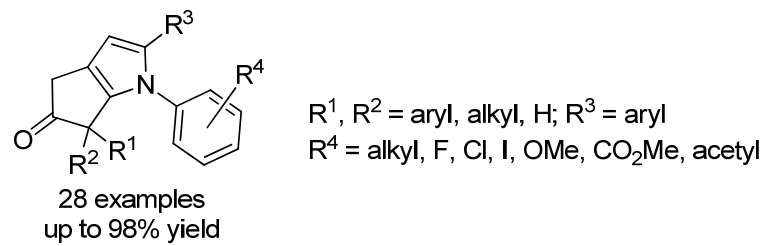

Scheme 22 One pot sequence between 2-furylcarbinols and anilines for pyrrole construction

Shao and co-workers ${ }^{[46]}$ reported a $\mathrm{Zn}(\mathrm{OTf})_{2}$-catalyzed synthesis of 3-polyhydroxyalkyl-substituted pyrrole derivatives via the coupling reaction between 1,2-cyclopropanated sugars and amines in 2015 (Scheme 23). The corresponding 1,4-dicarbonyl type of intermediate was generated by a Zinc-catalyzed ring opening of cyclopropane moiety.

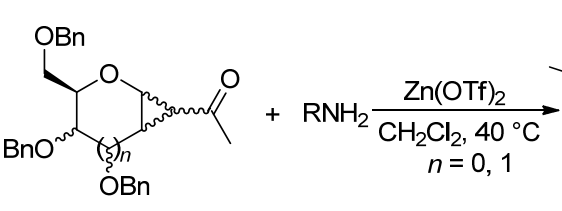

$\mathrm{R}=\mathrm{aryl}$, alkyl, Bn, propargyl, allyl<smiles>[R]n1cc(C(OCc2ccccc2)C(O)OCc2ccccc2)cc1C</smiles>

26 examples up to $93 \%$ yield

Scheme 23 Zinc-mediated cyclization process between 1,2cyclopropanated sugars and amines

Using carbohydrates and primary amines as substrates, Koo and co-workers ${ }^{[4]}$ also published a one-pot conversion method for the synthesis of pyrrole-2-carbaldehydes in the presence of oxalic acid as promoter, and applied it to the synthesis of 2-benzyl and 2-methylpyrrolo[1,4]oxazin-3one, lobechine and (-)-hanishin (Scheme 24).

Other than the strategies above, N1 unit related $[4+1]$ mode also could go through intermediates that have been used in the $[5+0]$ cyclization strategy. In 2015, a copper-

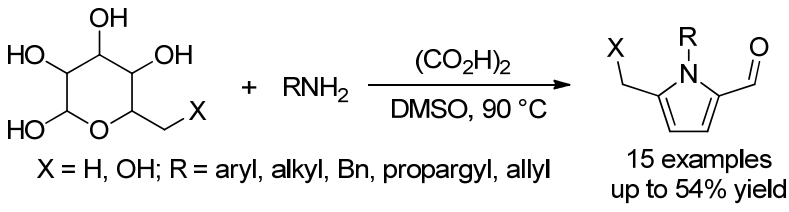

Scheme 24 Oxalic acid promoted reaction of carbohydrates and primary amines

catalyzed addition/cyclization cascade via a homopropargyl amine intermediate was developed by Punniyamurthy et $a l{ }^{[48]}$ affording 3-nitro substituted pyrroles in good yields (Scheme 25).

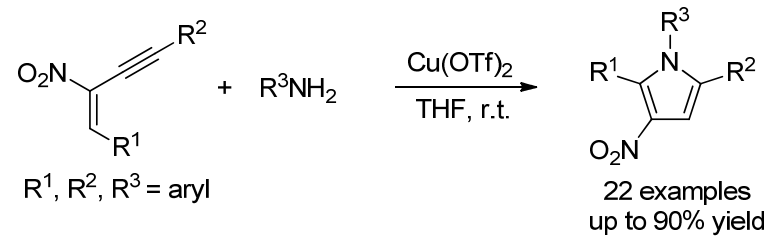

Scheme 25 Copper-catalyzed cyclization between 1,3-enynes with aromatic amines

Using 3-en-1-ynamides as substrates, Ye and co-workers ${ }^{[49]}$ exploited a gold-catalyzed $[4+1]$ cyclization with benzyl azides via a Nazarov cyclization of in situ generated gold-carbene intermediate leading to a series of 2-aminopyrroles in moderate to good yields (Scheme 26). Compared with known literature report, this reaction features high flexibility and mild reaction conditions.

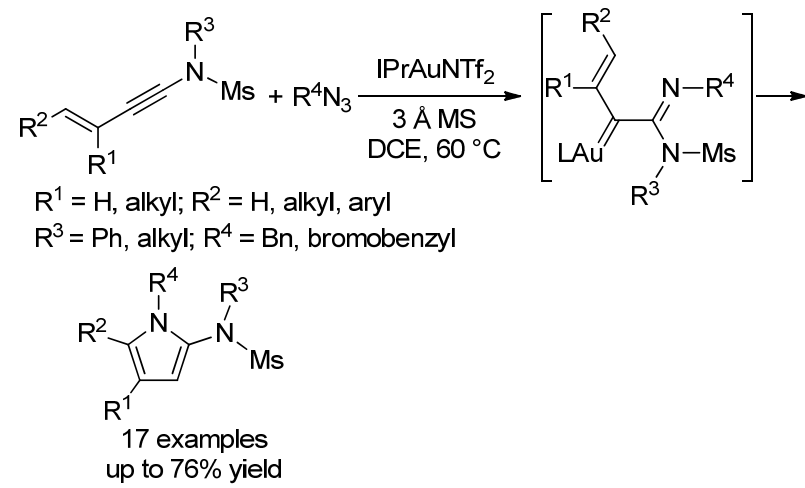

Scheme 26 Gold-catalyzed cyclization of benzyl azides and 3-en-1-ynamides

Liu's group has contributed a series of systematic studies on functionalization of alkene/alkyne/enyne type of compounds. As an part of their studies on nitrone involved methodology development, Liu and co-workers ${ }^{[50]}$ described a gold-catalyzed $\mathrm{N}, \mathrm{O}$-functionalization of 1,4-diyn3 -ols with $N$-hydroxyanilines giving multisubstituted pyrroles (Scheme 27). This reaction shows very broad substrate scope, and has been applied to the synthesis of a known PED4 inhibitor. During this reaction, an oxygen transfer/ $a z a$-Nazarov cyclization cascade of in situ generated nitrone was proposed. 
<smiles></smiles>

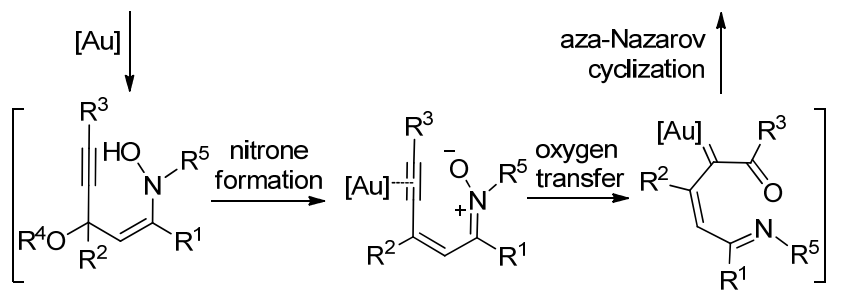

$\mathrm{R}^{1}, \mathrm{R}^{3}=$ aryl, alkyl, vinyl; $\mathrm{R}^{2}=$ alkyl $\mathrm{R}^{4}=$ alkyl, $H ; R^{5}=$ aryl

38 examples up to $93 \%$ yield

Scheme 27 Gold-catalyzed cyclization of 1,4-diyn-3-ols with $N$-hydroxyanilines

Following their research results on isoxazole based cyclization, Liu and co-workers ${ }^{[51]}$ also developed a goldcatalyzed $[4+1]$ annulation reactions for the construction of pyrrole core using 1,4-diyn-3-ols and isoxazoles as substrates (Scheme 28). Based on the reaction results, an interesting 1,2-alkyne migration was proposed for this transformation.

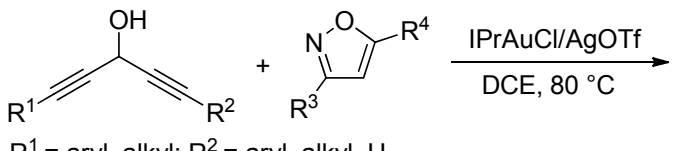

$\mathrm{R}^{1}=$ aryl, alkyl; $\mathrm{R}^{2}=$ aryl, alkyl, $\mathrm{H}$

$\mathrm{R}^{3}, \mathrm{R}^{4}=\mathrm{H}$, aryl, alkyl<smiles>[R][R]C(=O)c1cc([R])n(C([R])=CC([R1])=O)c1[R]</smiles>

Scheme 28 Gold-promoted reaction of 1,4-diyn-3-ols and isoxazoles

Subsequently, they further extended such a strategy to 4-methoxy-1,2-dienyl-5-ynes and anthranils, which could go through a gold-catalyzed $[4+1]$-annulations to yield 1,2,3,5-tetrasubstituted pyrroles (Scheme 29). ${ }^{[52]}$

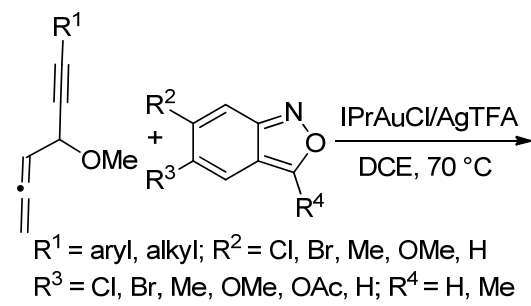<smiles>[R]C(=O)c1cc([R])c([R])cc1-n1c([R])ccc1C</smiles>

18 examples up to $76 \%$ yield

Scheme 29 Gold-catalyzed cyclization between 4-methoxy1,2-dienyl-5-ynes and anthranils

\subsection{C1 unit participated mode}

As for the $\mathrm{C} 1$ unit related strategies, allylic amines or propargyl amines are more often used substrates due to the nucleophilicity of the corresponding nitrogen atom.

In 2015, Jun and co-workers ${ }^{[53]}$ published a Rhodium(III) catalyzed coupling reaction between allylamines and alkenes in the presence of AgOAc affording substituted pyrroles (Scheme 30). However, the alkene substrates are limited to alkenes possessing electron-withdrawing groups.

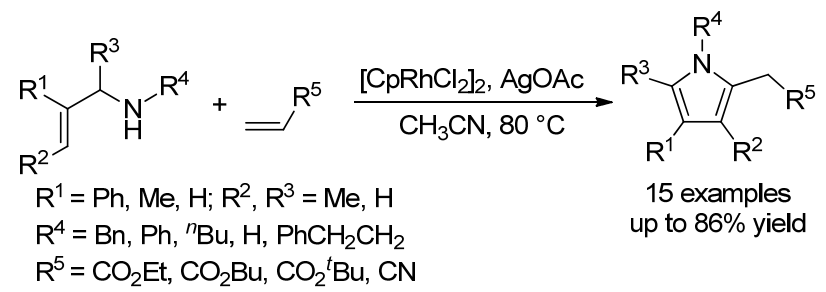

Scheme 30 Rhodium and silver-catalyzed reaction of allylamines and alkenes

In the same year, Sakai and co-workers ${ }^{[54]}$ developed a highly efficient $\mathrm{CuCl}_{2}$-catalyzed [4+1] annulation of propargylamines with $\mathrm{N}, \mathrm{O}$-acetals leading to the generation of polysubstituted pyrroles (Scheme 31 ). Based on this transformation, they further developed a simplified version by employing ethyl glyoxylate and pyrrolidine as $\mathrm{N}, \mathrm{O}$-hemiacetal source, which could be converted to the corresponding pyrroles with propargylamines under the catalysis of copper(II) chloride. ${ }^{[55]}$ However, both substrate scope and reaction yields were affected.

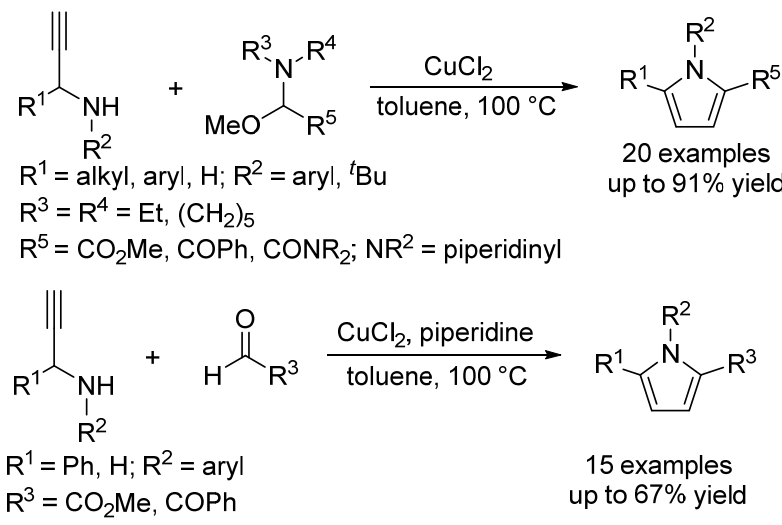

Scheme 31 Copper catalyzed annulation of propargylamines

Using $\alpha$-tosylamide allenes and alkynes as substrates, Bäckvall and co-workers ${ }^{[56]}$ successfully developed a one-pot strategy for the synthesis of substituted pyrroles via the catalysis of $\mathrm{Pd}(\mathrm{OAc})_{2}$ (Scheme 32$)$. In the presence of the tosylamide moiety, the first coupling reaction could proceed regiospecifically toward the final cyclization. Moreover, the chemoselectivity of this tandem reaction could be controlled by the solvent used leading to the selective synthesis of (Z)-tetrasubstituted olefins or 2,5-dihydropyrroles. 

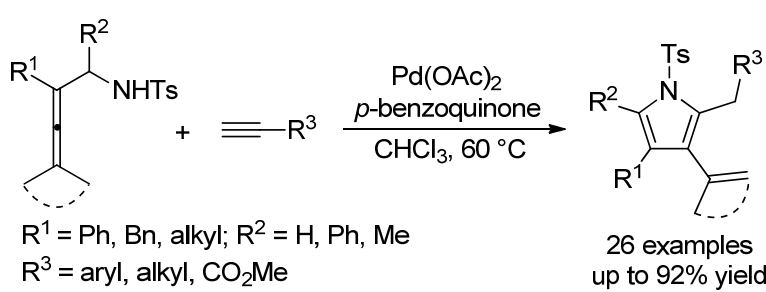

26 examples up to $92 \%$ yield

Scheme 32 Palladium-promoted pyrrole synthesis between $\alpha$-tosylamideallenes and alkynes

Besides above amines, imine type of compound has also been used in such a $[4+1]$ cyclization mode. In 2016, Arndtsen and co-workers ${ }^{[57]}$ reported a palladium-catalyzed multicomponent reaction to generate polycyclic pyrroles from alkyne-tethered imines, aryl iodides and CO (Scheme 33). This reaction utilized the dicarbonylative formation of Münchnone, which cyclized spontaneously with tethered alkynes to give polycyclic pyrroles. Through the modification of the reaction conditions, the authors also achieved the selective introduction of two different aryl group $\left(\mathrm{R}^{3}\right.$ and $\mathrm{R}^{4}$ ) to the products.

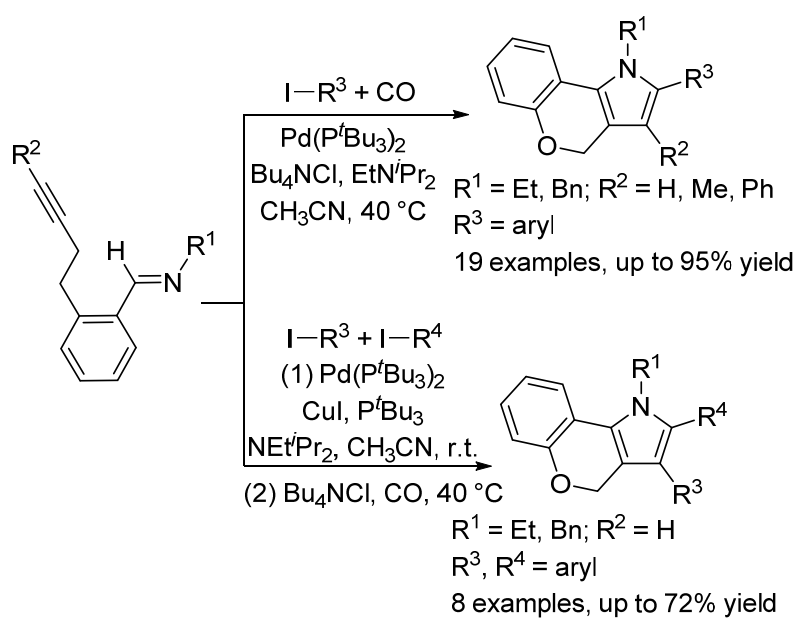

Scheme 33 Palladium-catalyzed reaction of imines, aryl iodides and $\mathrm{CO}$

In 2017, Xiao and co-workers ${ }^{[58]}$ reported a $[4+1]$ cycloaddition reaction of sulfurylides and $\alpha, \beta$-unsaturated imines for preparation of polysubstituted pyrroles through a formal $[4+1]$ cycloaddition/E1cb elimination/aromatization process (Scheme 34). Such a reaction features simple operation, high efficiency, mild and metal-free conditions, and the readily available starting materials.

$$
\begin{aligned}
& \mathrm{R}_{\mathrm{R}^{2}=\mathrm{Me}, \mathrm{Et}, \mathrm{Bn},{ }^{\mathrm{B}} \mathrm{Bu} ; \mathrm{R}^{2}=\text { aryl }}^{\mathrm{CO}_{2} \mathrm{R}^{1}} \mathrm{R}^{3} \mathrm{OC} \\
& \mathrm{R}^{3}=\text { aryl, alkyl, OEt }
\end{aligned}
$$

Scheme 34 Cycloaddition reaction of sulfurylides and $\alpha, \beta$ unsaturated imines

Based on the special chemical property of isoxazole in pyrrole synthesis, Liu group ${ }^{[59]}$ reported a $[4+1]$ cyclization of isoxazoles and propiolate derivatives (Scheme 35). This reaction should be initiated by a $O$-attack pathway to the seven-membered intermediate followed by an intramolecular cyclization/1,5-acyl shift/1,5-hydrogen shift to give the substituted pyrroles.

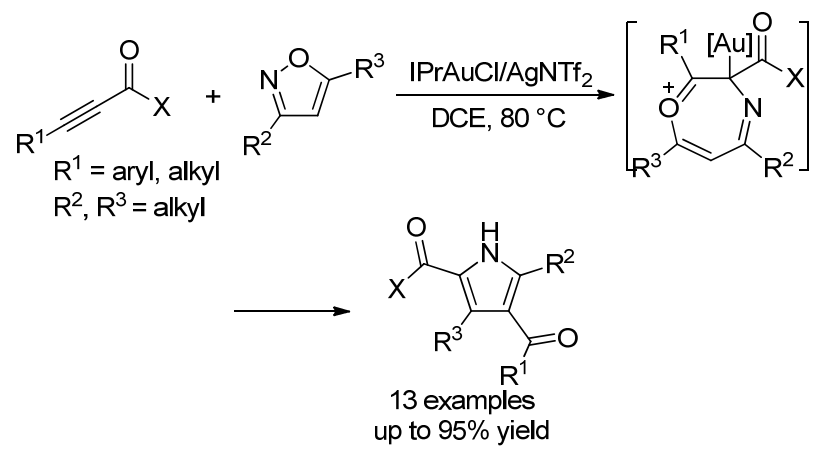

Scheme 35 Gold-promoted cyclization of isoxazoles and propiolate

Interestingly, the substituent pattern of isoxazoles affects the reaction results clearly. If there was no substituent on the isoxazole ring, 3,8-dicarbonylimidazo[1,2-a]pyridines would be obtained.

\section{$3[3+2]$ mode}

Formal [3+2] mode is the most commonly used cyclization way for pyrrole synthesis due to the following reasons. First, lots of combinations could propose for such a reaction mode. Second, since only two substrates are involved, corresponding reaction condition optimization is relatively easy. Accordingly, recent work on this mode will be introduced based on the structural feature of the substrates.

\subsection{Amine and related derivatives as substrates}

As a big group of substrates for pyrrole synthesis, amine and related derivatives are usually readily available. Therefore, most of recent results were focused on the development of new catalytic system.

In 2016, following their research results in the synthesis of 2,3-disubstituted furans, Cheng and co-workers ${ }^{[60]}$ reported a tandem coupling/cyclization reaction between methylene ketones and diethanolamines affording substituted pyrroles with a 2-hydroxyethyl at 1-position (Scheme 36). During this procedure, a coupling of two radical intermediates generated by $\alpha$-hydrogen abstraction of two substrates was proposed.

As mentioned in $[4+1]$ mode section, catalytic dehydrogenation of alcohols, as an important and practical way for the synthesis of carbonyl compounds, has received considerable attentions in recent years, and also been applied to the construction of pyrrole ring through $[3+2]$ mode, of which the simplest retrosynthetic way is from the combination of $\beta$-amino alcohol and substituted ethanol. 


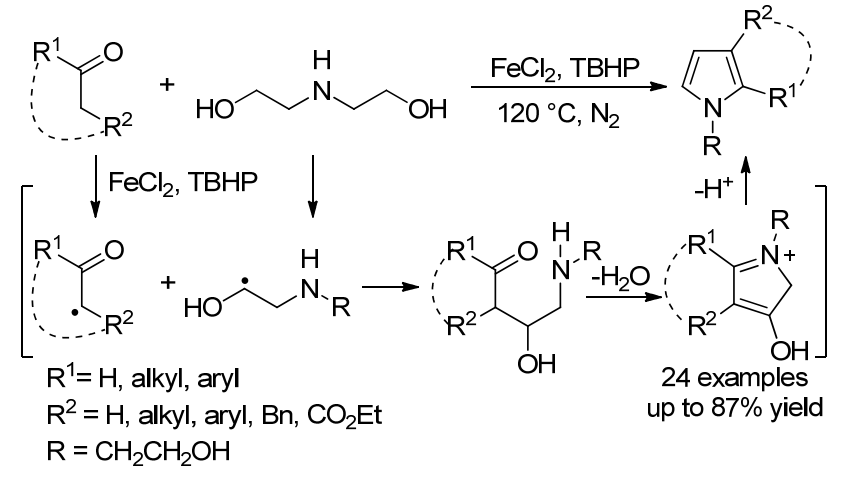

Scheme 36 Fe-promoted cyclization reaction between methylene ketones and diethanolamines

Using this strategy, Shimizu and co-workers ${ }^{[61]}$ described the synthesis of 2,5-disubstituted pyrroles via dehydrogenative condensation of secondary alcohols and 1,2-amino alcohols under the catalysis of $\mathrm{Pt} / \mathrm{C}$ in 2016 (Scheme 37).

$$
\begin{aligned}
& \mathrm{R}^{1}=\text { alkyl, } \mathrm{Ph} \\
& \mathrm{R}^{2}=\text { alkyl, aryl }
\end{aligned} \mathrm{R}_{\mathrm{R}^{2}}^{\mathrm{NH}_{2}} \frac{\mathrm{Pt/ \textrm {C } , \mathrm { KO } ^ { t } \mathrm { Bu }}}{\text { diglyme, } 125{ }^{\circ} \mathrm{C}}
$$

Scheme 37 Pt/C-catalyzed annulation of secondary alcohols and 1,2-amino alcohols

Based on their interest in metal-catalyzed sustainable synthesis of heterocycles, Kempe and co-workers ${ }^{[62]}$ reported the first base-metal-catalyzed synthesis of pyrroles from alcohols and amino alcohols (Scheme 38). The reaction proceeds under mild conditions at manganese catalyst loading as low as $0.5 \mathrm{~mol} \%$, and has a broad substrate scope and attractive functional-group tolerance. Later on, $\mathrm{Yu}^{[63]}$ and Balaraman ${ }^{[64]}$ groups also published similar type of cyclization reaction using their own pincer-type $\mathrm{Ru}(\mathrm{II})$ NNP complex and sulphur based SNS-cobalt(II) pincer complexes as catalysts, respectively.

$$
\begin{aligned}
& \mathrm{R}^{1}=\text { alkyl, aryl; } \mathrm{R}^{2}=\mathrm{H} \text {, alkyl } \\
& \mathrm{R}^{3}=\text { alkyl, } \mathrm{Ph}, \mathrm{Bn}
\end{aligned}
$$

Scheme 38 Manganese-catalyzed pyrrole synthesis from alcohols and amino alcohols

As a continuation of Liu and $\mathrm{Li}$ group ${ }^{[65]}$ on goldcatalyzed methodology development, a gold-catalyzed synthesis of substituted pyrroles via a hydroamination/ cyclization cascade of $\alpha$-amino ketones and alkynes was reported in 2015 (Scheme 39). During the substrate scope investigation, high regioselectivity was achieved by choosing proper alkyne substrates, and it should be noted that $N$-Ts and $N-\mathrm{Bz}$ protected aminoketones were not applicable to this reaction.

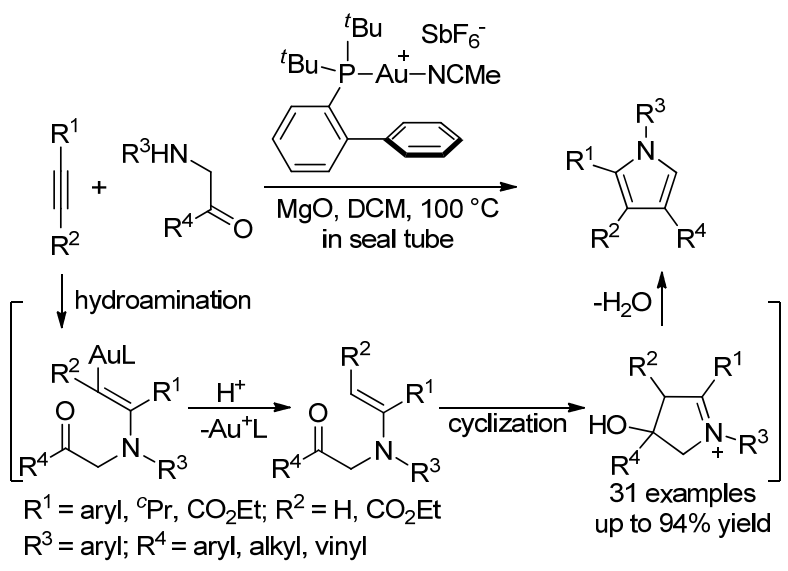

Scheme 39 Gold-catalyzed cyclization of $\alpha$-amino ketones and alkynes

In 2016, a Lewis base-catalyzed [3 + 2] cyclization/ aromatization process was described by Tong and co-workers (Scheme 40). ${ }^{[66]}$ In such a tandem procedure, 2-aminoketone derivatives were used as N1C2 bisnucleophile units to react with $\beta^{\prime}$-acetoxyallenoate affording 2,3,4-trisubstituted pyrroles in moderate to good yields. Additionally, when 1,4-dithane-2,5-diol was used as the bisnucleophile partner, fully substituted thiophene-2-carbaldehyde could be obtained through this reaction protocol.

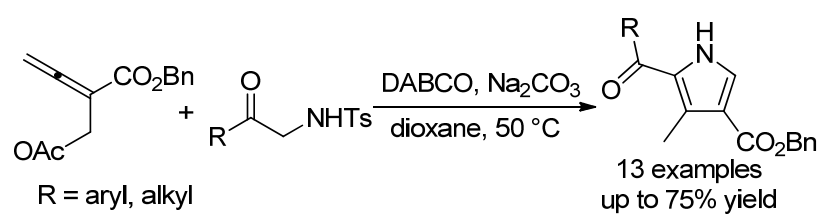

Scheme 40 Lewis base-catalyzed cyclization protocol of 2aminoketones with $\beta^{\prime}$-acetoxyallenoate

Enamine is also a very common $\mathrm{C} 2 \mathrm{~N} 1$ unit used for pyrrole synthesis, and a nucleophilic addition is normally the first step for corresponding cyclization process. Among the electrophiles, alkynes are used more often in the past several years since the pioneering work of Stuart and Glorius et al. ${ }^{[67-68]}$ In 2015, inspired by the work of Yoshida, ${ }^{[69]}$ $\mathrm{Hu}$ and co-workers ${ }^{[70]}$ developed a copper-catalyzed cycloaddition of propargylic esters with $\beta$-enamino esters to generate pyrroles in the presence of nonchiral P,N,N-ligand (Scheme 41). During such a reaction, a $\mathrm{Cu}$-allenylidene intermediate was proposed for the key nucleophilic addition step. A very similar reaction model under microwave irradiation was also reported by Cui and co-workers ${ }^{[71]}$ in 2016.

After developing a method on the synthesis of $\alpha$-enamino esters from $\alpha$-amino acid esters, Xie and co-workers ${ }^{[72]}$ presented a oxidative coupling reaction between $\alpha$-enamino esters and activated alkynes under $\mathrm{Cu}(\mathrm{II})$-promoted conditions to form polysubstituted pyrroles in high yields (Scheme 42). In this methodology, $\alpha$-enamino esters were used for the first time as the substrates for the synthesis of 

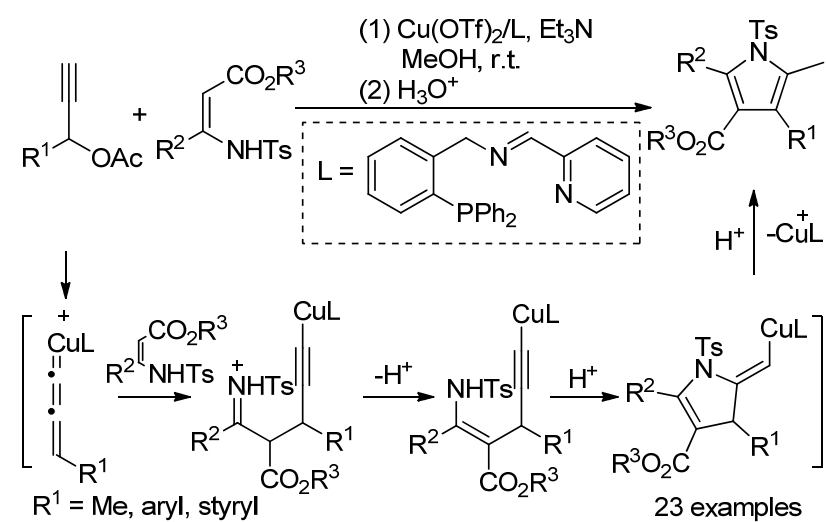

$\mathrm{R}^{2}=\mathrm{Me}$, aryl; $\mathrm{R}^{3}=\mathrm{Me}, \mathrm{Et}$

up to $90 \%$ yield

Scheme 41 Copper-catalyzed cycloaddition of propargylic esters with $\beta$-enamino esters

polysubstituted pyrroles.

$$
\begin{aligned}
& \mathrm{R}^{1}=\mathrm{Me}, \mathrm{Et}, \mathrm{Bn} ; \mathrm{R}^{2}=\mathrm{Me}, \mathrm{Et} \quad \frac{\mathrm{Cu}(\mathrm{OAc})_{2}, \mathrm{PdCl}_{2}}{t-\mathrm{AmOH}, 120^{\circ} \mathrm{C} \mathrm{R}^{1} \mathrm{O}_{2} \mathrm{C}} \\
& \mathrm{CO}^{1} \mathrm{O}_{2} \mathrm{C} \mathrm{R}_{2}
\end{aligned}
$$

Scheme $42 \mathrm{Cu}(\mathrm{II})$-promoted annulation of $\alpha$-enamino esters and activated alkynes

In 2016, Zhang and co-workers ${ }^{[73]}$ reported a regioselective cobalt-catalyzed synthesis of pyrroles from enamides and alkynes in the present of AgOTf and CuO (Scheme 43). This synthesis system presented excellent substrate toleration and regioselectivity, and the carbon-carbon and carbon-nitrogen bonds were simultaneously constructed. In the same year, Pawar and co-workers ${ }^{[74]}$ also published a very similar reaction using same strategy.

$$
\begin{aligned}
& { }_{\mathrm{R}^{1}=\mathrm{H}, \text { aryl, } \mathrm{CO}_{2} \mathrm{Me} \text {, cyclopropyl }}^{\mathrm{R}^{1}}=\mathrm{O}+\|_{\mathrm{R}^{2}}^{\mathrm{R}^{2}} \frac{\mathrm{CpCo}(\mathrm{CO}) \mathrm{l}_{2}, \mathrm{AgOTf}, \mathrm{KOAc}}{\mathrm{CuO}, \mathrm{CF}_{3} \mathrm{CH}_{2} \mathrm{OH}, \text { air, } 100{ }^{\circ} \mathrm{C}} \\
& { }^{n} \mathrm{Pr} ; \mathrm{R}^{3}=\mathrm{H} \text {, aryl, alkyl, } \mathrm{CO}_{2} \mathrm{Et}
\end{aligned}
$$

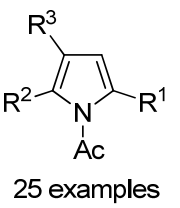
up to $93 \%$ yield

Scheme 43 Cobalt-catalyzed cycloaddition of enamides and alkynes

Using enamines and allenes as substrates, Deng and Luo et al. ${ }^{[75]}$ developed an $\mathrm{I}_{2}$-catalyzed tandem reaction affording polysubstituted pyrroles in moderate to excellent yields through a Michael addition/oxidative annulation pathway (Scheme 44). Especially, high regioselectivities could be obtained when unsymmetric allenes were used.

Under the catalysis of $\mathrm{I}_{2}$, an annulation between $N$ methyl- $N$ - $[(E)-1-($ methylsulfanyl)-2-nitro-1-ethenyl $]$ amine and $\beta$-nitrostyrene was developed by Shanmugam and co-workers (Scheme 45) ${ }^{[76]}$ Moreover, some of the pyrrole products showed good activities against a panel of Gram positive and negative infectious pathogens.

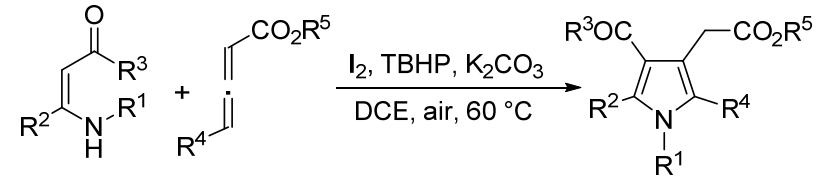

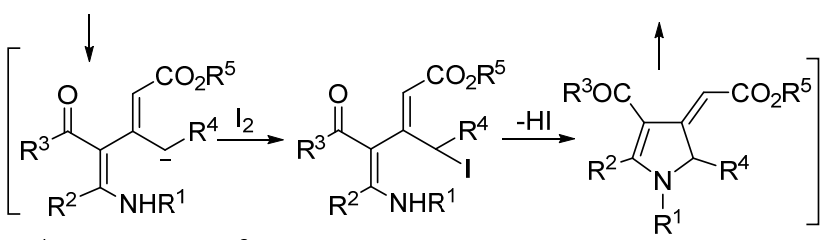

$\mathrm{R}^{1}=\mathrm{Et}, \mathrm{Bn}$, aryl; $\mathrm{R}^{2}=$ aryl, alkyl; $\mathrm{R}^{3}=\mathrm{OMe}, \mathrm{OEt}, \mathrm{OBn}, \mathrm{O}^{\prime} \mathrm{Pr}, \mathrm{O}^{t} \mathrm{Bu}, \mathrm{Ph}$; $\mathrm{R}^{4}=\mathrm{Et}, \mathrm{CO}_{2} \mathrm{Et}, \mathrm{Bn},{ }^{n} \mathrm{Bu}$, aryl; $\mathrm{R}^{5}=\mathrm{Me}, \mathrm{Et}$

25 examples up to $91 \%$ yield

Scheme $44 I_{2}$-catalyzed reaction between enamines and allenes

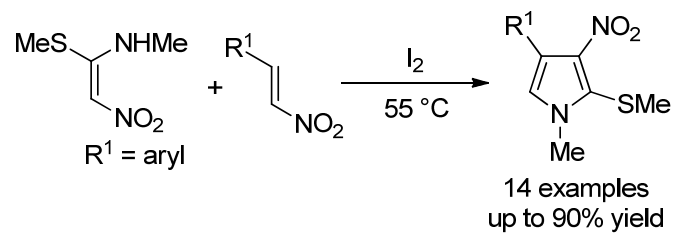

Scheme $45 \quad \mathrm{I}_{2}$-catalyzed annulations of $\beta$-nitrostyrene

In 2015, Jin and co-workers ${ }^{[77]}$ reported a $\mathrm{K}_{3} \mathrm{PO}_{4}$ catalyzed coupling reaction between propargyl amines and activated alkynes affording multisubstituted pyrroles (Scheme 46). This reaction went through a Michael addition/alkyne carbocyclization process. Interestingly, changing the base catalyst to $\mathrm{CsF}$ led to different pyrrole products through a Michael addition/aza-Claisen rearrangement/ cyclization sequence. In 2017, a similar type of cyclization reactions have also been described by Hua et al. ${ }^{[78]}$ using silver catalyst.

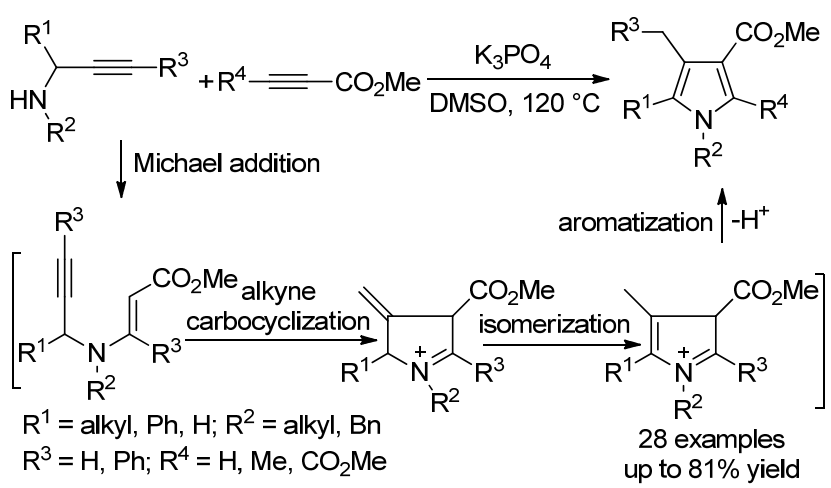

Scheme $46 \quad \mathrm{~K}_{3} \mathrm{PO}_{4}$-catalyzed cyclization between propargyl amines and activated alkynes

Using propargylamines and ethyl vinyl ether as substrates, Castagnolo and co-workers ${ }^{[79]}$ developed a microwave promoted enyne cross metathesis reaction giving substituted pyrroles (Scheme 47). As the first enyne cross metathesis reaction to form pyrroles, this one-pot procedure also features high reaction speed and has been applied to the synthesis of a natural alkaloid. 


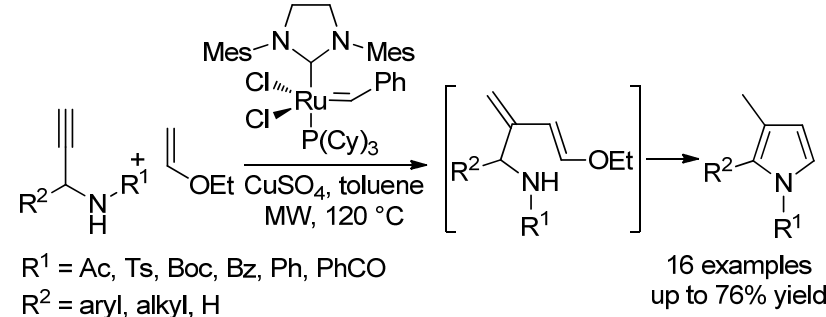

Scheme 47 Rhodium-promoted annulation of propargylamines and ethyl vinyl ether

In 2016, an efficient synthesis of multisubstituted pyrroles via a copper-catalyzed tandem three-component reaction was developed by Wang and co-workers (Scheme 48). ${ }^{[8]}$ In this reaction, an interesting nucleophilic addition/cyclization/aromatization cascade of very basic chemicals, i.e., aromatic alkenes/alkynes, trimethylsilyl cyanide and $N, N$-disubstituted formamides, has been proposed with the generation of the key $\alpha$-aminonitrile intermediates.

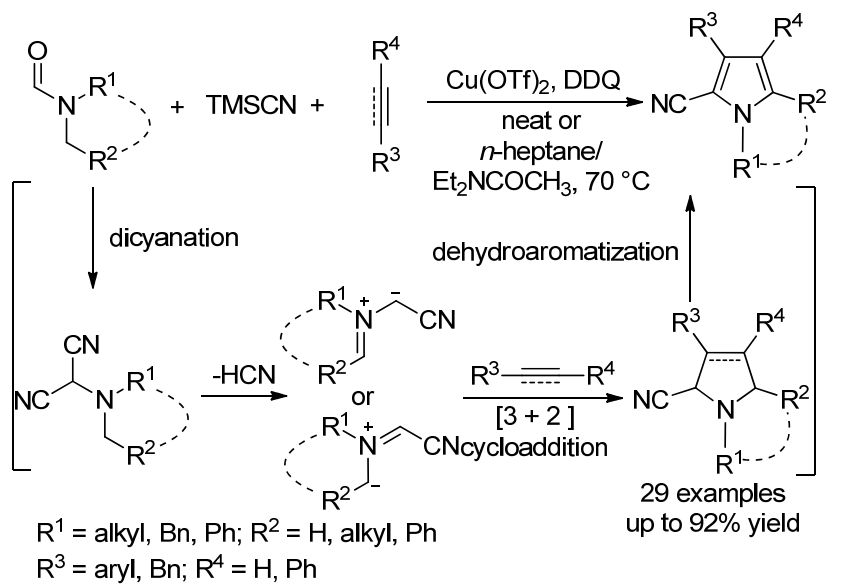

Scheme 48 Copper-catalyzed three component reaction for pyrrole synthesis

In 2019, $\mathrm{Hu}$ group $^{[81]}$ described a 1,5-dizzabicyclo[5.4.0] undecen-5-ene (DBU)-promoted method for the synthesis of pyrroles from $\alpha, \beta$-unsaturated ynones and $N$-substituted ethyl glycine ethyl ester hydrochlorides in good yields (Scheme 49). This protocol is a transition-metal-free tandem Michael-addition/cyclization process, which shows advantages of mild reaction conditions, readily available starting materials and a wide scope of substrates.

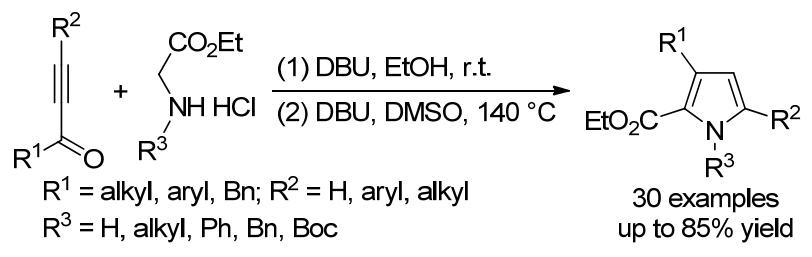

Scheme 49 DBU-promoted annulation of ynones and $\mathrm{N}$-substituted ethyl glycine ethyl ester

\subsection{Isocyanides as substrates}

Isocyanides are also one kind of popular substrate used for pyrrole synthesis via $[3+2]$ mode as N1C2 unit. In 2015, Yang and co-workers ${ }^{[2]}$ reported a silver-catalyzed strategy to construct substituted-pyrroles from isocyanides and chromones (Scheme 50). This reaction could produce polysubstituted pyrroles in good yields through a Michael addition/cyclization/isomerization process.

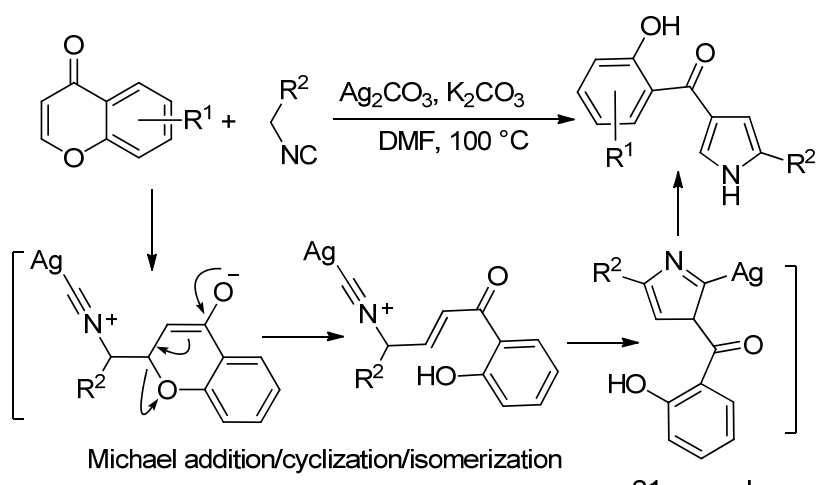

$\mathrm{R}^{1}=\mathrm{H}$, alkyl, OMe, $\mathrm{Ph}, \mathrm{F}, \mathrm{Cl}, \mathrm{Br}$ $\mathrm{R}^{2}=\mathrm{CO}_{2} \mathrm{Me}, \mathrm{CO}_{2} \mathrm{Et}, \mathrm{Ph}$

21 examples up to $98 \%$ yield

Scheme 50 Silver-catalyzed cyclization of isocyanides and chromones

Similar type of products could also be obtained by using methyl isocyanoacetate and aurone analogues under transition-metal-free conditions (Scheme 51). ${ }^{[83]}$ This procedure reported by Shao and co-workers could yield pyrroles in excellent yields through a cycloadduct intermediate, and features operational simplicity and atom economy.

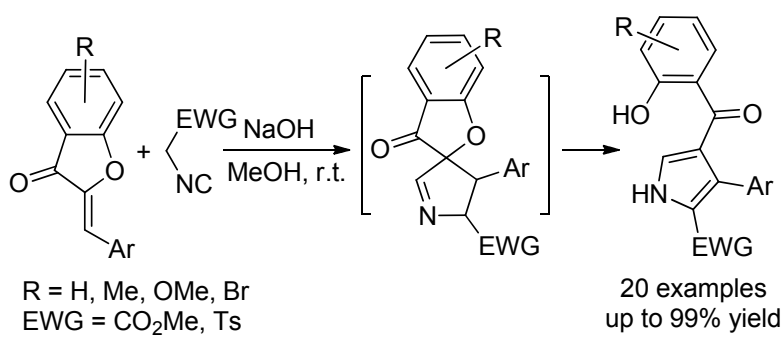

Scheme 51 Cyclization between methyl isocyanoacetate and aurone analogues

Different from above ring opening step for final aromatization, a ring expansion of corresponding spirocyclic intermediate was observed during a one-pot synthesis of 6to 8-membered pyrrololactams by $\mathrm{Oh}$ and co-workers (Scheme 52). ${ }^{[84]}$ This procedure was achieved through the alkyne-isocyanide cycloaddition followed by a spontaneous ring expansion of spiro- $2 H$-pyrrole.

Using ethyl allenoates and activated isocyanides as substrates, $\mathrm{Yu}$ and $\mathrm{Lu}$ et al. ${ }^{[85]}$ developed a copper-catalyzed cyclization reaction for the synthesis of substituted pyrroles (Scheme 53). During this process, an interesting elimination and re-addition of the EWG group was observed. 

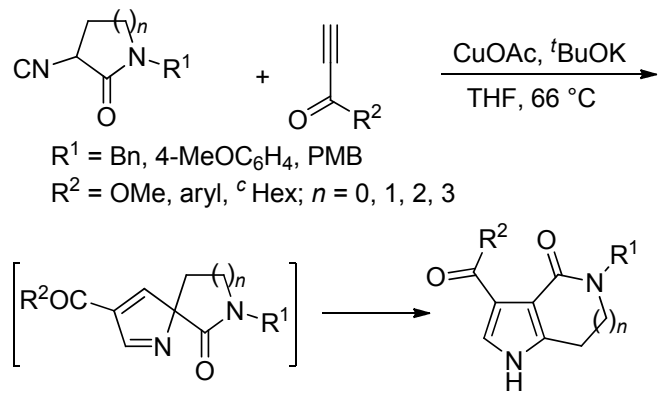

23 examples up to $82 \%$ yield

Scheme 52 Copper-catalyzed alkyne-isocyanide cycloaddition/ring expansion reaction

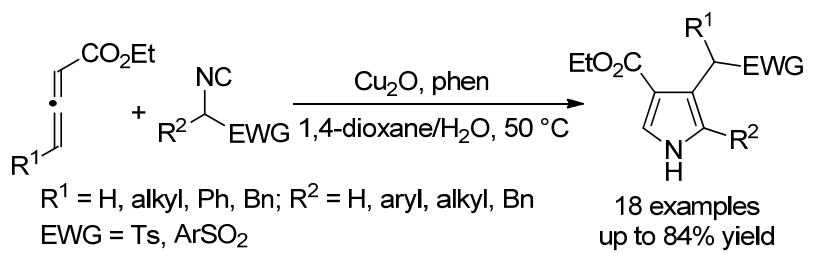

Scheme 53 Copper-catalyzed cyclization of ethyl allenoates and activated isocyanides

Other than Yu's results, a different cyclization pattern of allenoates was reported by Zhao and co-workers ${ }^{[86]}$ with the use of $\mathrm{PPh}_{3}$ as Lewis base catalyst (Scheme 54). During this reaction, the 1,4-addition of $\mathrm{PPh}_{3}$ to allenoates was the key for such a reaction mode. Along with this reaction, they also developed an Ag-catalyzed enantioselective cyclization of activated isocyanides with allenoates to give $3 H$-pyrroles.

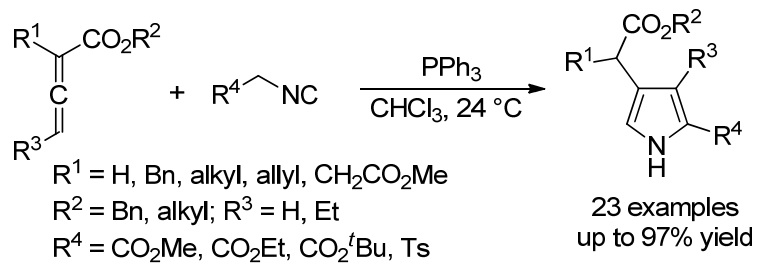

Scheme $54 \mathrm{PPh}_{3}$-promoted cyclization of allenoates with activated isocyanides

In $2017, \mathrm{Bi}, \mathrm{Fu}$ and co-workers ${ }^{[87]}$ reported a silvercatalyzed cascade reaction for the construction of pyrroles from $\beta$-enaminones and isocyanoacetates (Scheme 55). In this process, an unprecedented ring-opening of 2-imidazoline intermediate was firstly reported due to the EWGs on the $\alpha$-position of $\beta$-enaminone. A similar type of transformation was also reported by Zhao and co-workers ${ }^{[88]}$ using isocyanoacetates, amines and 3-formylchromones as substrates.

Other than the $\mathrm{C} 2 \mathrm{~N} 1$ unit, isocyanide has also been used as $\mathrm{C} 1 \mathrm{~N} 1$ unit in $[3+2]$ cyclization mode. In 2016, Xu, Zhang, Liu and co-workers ${ }^{[89]}$ developed an expeditious synthesis of pyrrolo[3,4-b]indoles through a cross-cycloaddition reaction between isocyanides and 2-isocyanochalcones (Scheme 56). In this practical procedure, two different isocyanides could undergo heterodimerization and subsequent $[3+2]$-cycloaddition/isomerization of the

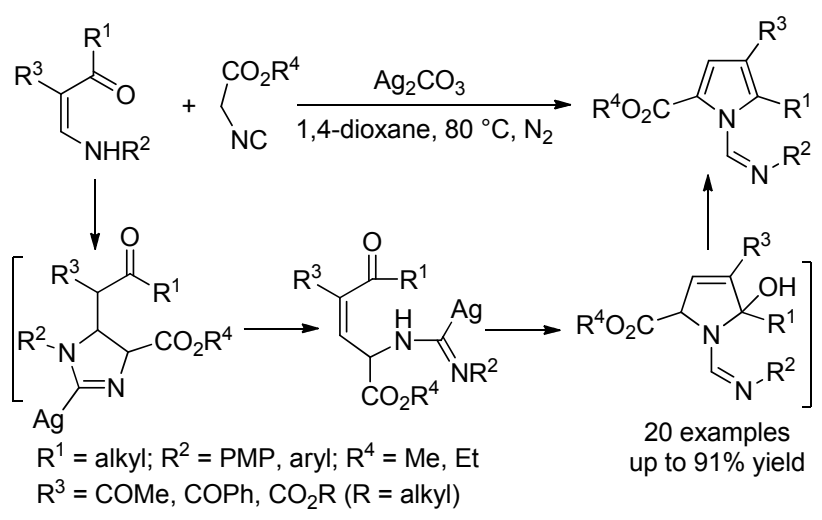

Scheme 55 Silver-catalyzed reaction of $\beta$-enaminones and isocyanoacetates

1,4-diazabutatriene intermediate to generate pyrrolo[3,4-b]indoles.

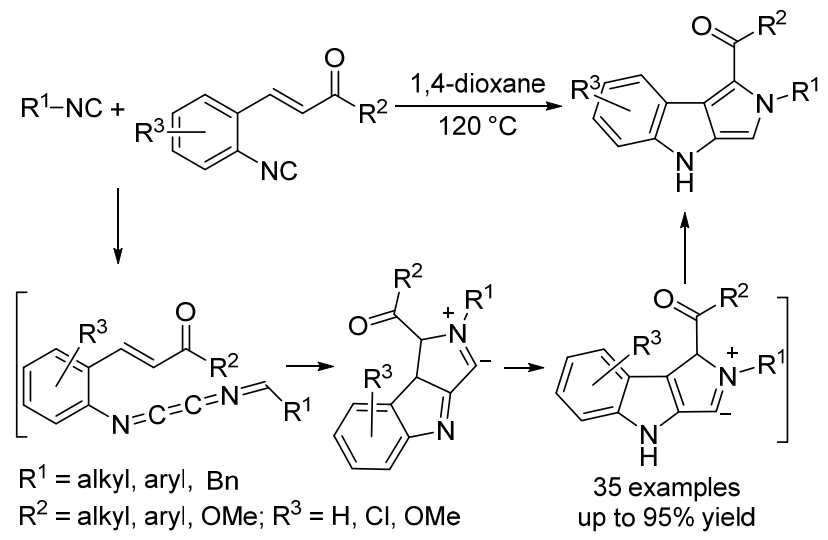

Scheme 56 Tandem cyclization of isocyanides and 2-isocyanochalcones

In 2018, Jia and Li et al. ${ }^{[90]}$ also described a tandem reaction for the synthesis of pyrrole-fused heterocycles using $\mathrm{Yb}(\mathrm{OTf})_{3}$ and $\mathrm{Ag}_{2} \mathrm{CO}_{3}$ as the cooperative catalysts. During this reaction, three consecutive nucleophilic addition steps between one enynone and two isocyanides would give the key amine intermediate, which went through a silver-induced 5-endo-dig cyclization step to afford the final product (Scheme 57).

\subsection{Isoxazole, $2 \mathrm{H}$-azirines and related derivatives as substrates}

Regarding pyrrole synthesis, isoxazole is one of typical versatile synthons, and has been used as both $\mathrm{N} 1$ unit in $[4+1]$ mode and N1C2 unit in [3+2] mode. In 2015, a novel gold-catalyzed synthesis of substituted 2-aminopyrroles via a formal [3+2] cycloaddition from isoxazoles and ynamides was reported by $\mathrm{Ye}, \mathrm{Lu}$ and co-workers (Scheme 58). ${ }^{[91]}$ This reaction involved an in situ generated key $\alpha$-imino gold carbene, which was formed from the substrates through an atom-economic manner.

Interesting, changing the $N$-substituents of ynamides to an oxazolidinone moiety led to the formation of fully substituted pyrroles in good yields (Scheme 59). ${ }^{[92]}$ 


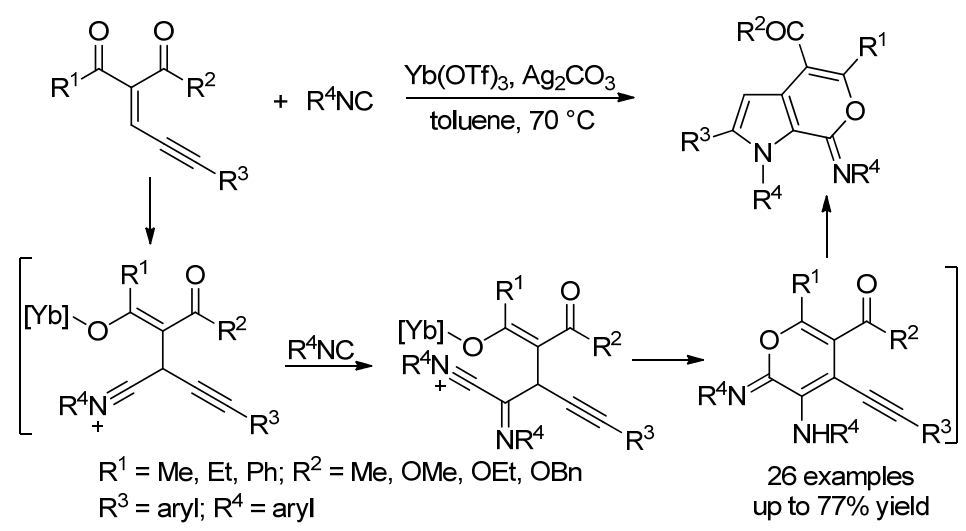

Scheme $57 \mathrm{Yb}(\mathrm{OTf})_{3}$ and $\mathrm{Ag}_{2} \mathrm{CO}_{3}$-catalyzed cyclization of enynones and isocyanides

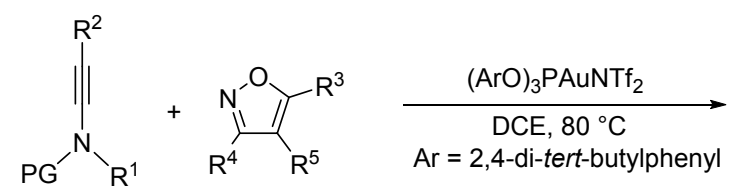<smiles>[R]C(=O)c1c([R])[nH]c(N([R])[O])c1[R]</smiles>
or<smiles>[R]c1[nH]c(N([R])[Po])c([R])c1[R7]</smiles>
$\mathrm{R}^{5}=\mathrm{H}$ $\mathrm{R}^{5} \neq \mathrm{H}$<smiles>C1CCCCC1</smiles>

\section{4 examples} up to $96 \%$ yield

15 examples

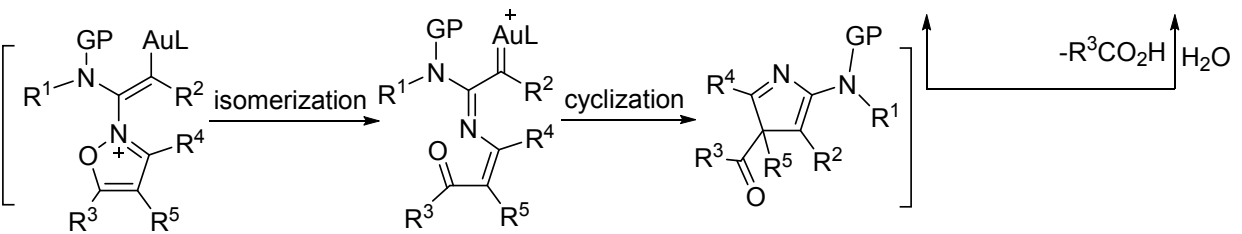

$\mathrm{R}^{1}=\mathrm{Ph}, \mathrm{Bn}$, alkyl; $\mathrm{R}^{2}=\mathrm{Ph}$, styryl, ${ }^{C} \mathrm{Pr} ; \mathrm{R}^{3}=\mathrm{H}, \mathrm{Me},{ }^{n} \mathrm{Bu}, \mathrm{Ph}, \mathrm{OMe}$ $\mathrm{R}^{4}=\mathrm{H}$, alkyl, aryl, styryl; $\mathrm{R}^{5}=$ aryl, $\mathrm{H}, \mathrm{Me},{ }^{n} \mathrm{C}_{9} \mathrm{H}_{19}, \mathrm{CO}_{2} \mathrm{Me}$

Scheme 58 Gold-catalyzed annulation between isoxazoles and ynamides

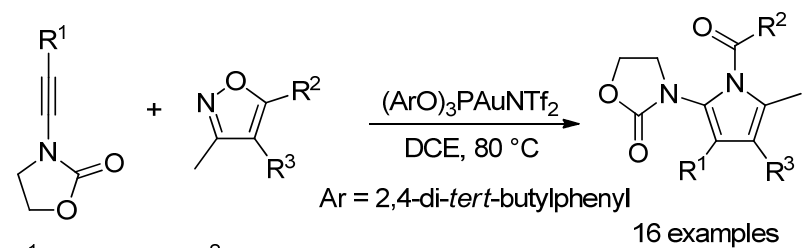

$\mathrm{R}^{1}=$ aryl, styryl; $\mathrm{R}^{2}=\mathrm{Et}$, phenethyl up to $99 \%$ yield $\mathrm{R}^{3}=$ alkyl, aryl, ester

Scheme 59 Gold-catalyzed cycloaddition between ynamides and isoxazoles

Khlebnikov and co-workers ${ }^{[93]}$ also developed a one-pot approach for the synthesis of methyl 4-aminopyrrole2-carboxylates from 5-methoxyisoxazoles and pyridiniumylides via $\mathrm{FeCl}_{2} / \mathrm{Et}_{3} \mathrm{~N}$ binary catalytic system followed by hydrazinolysis (Scheme 60).

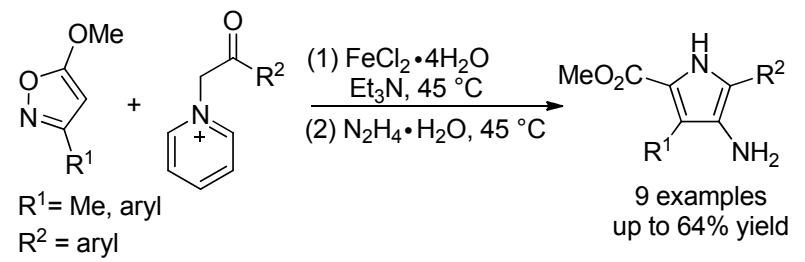

Scheme 60 One-pot pyrrole synthesis from 5-methoxyisoxazoles and pyridiniumylides
In 2016, Opatz and co-workers ${ }^{[94]}$ provided a directing method to synthesize tetrasubstituted pyrroles via a photochemical one-pot procedure (Scheme 61). Different from other literature reports, the key acylazirine intermediate was generated by UV irradiation.

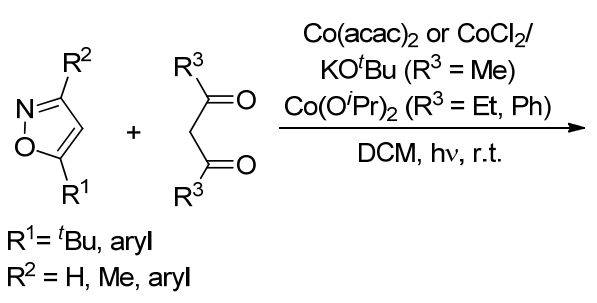<smiles>[R]C(=O)c1[nH]c([R])c(C([R])=O)c1[R]</smiles>

18 examples up to $94 \%$ yield

Scheme 61 Photo induced cobalt-catalyzed cyclization of isoxazoles and acetylacetone

In the same year, Kang and co-workers ${ }^{[95]}$ reported a one-pot iridium-complex-catalyzed cyclization/aromatization procedure for the synthesis of multiple substituted pyrroles (Scheme 62). For the first time, instead of isoxazoles, 2,3-dihydroisoxazoles were used along with chalcones as the substrates. Moreover, this protocol could also be used to synthesize pyrrolidines and carbazoles. 


$$
\begin{aligned}
& \mathrm{R}^{1} \\
& \mathrm{R}^{1}, \mathrm{R}^{2}=\text { aryl; } \mathrm{R}^{3}=\mathrm{Me}, \mathrm{Et} \\
& \mathrm{R}^{4}=\operatorname{aryl}, \mathrm{CO}_{2} \mathrm{Me} ; \mathrm{R}^{5}=\text { aryl, Me, OMe, styryl }
\end{aligned}
$$

Scheme 62 Iridium-catalyzed cycloaddition between 2,3-dihydroisoxazoles and chalcones

As a special derivative of isoxazole, Münchnone has also been used by chemists for the construction of pyrrole skeleton. Although good regioselectivity could be achieved with the use of arylacetylene as another cyclization substrate, the cyclization reaction with alkene was quite complicated. To overcome such a drawback, Harrity and co-workers ${ }^{[96]}$ developed an amine catalysed regioselective cyclization between 1,3-oxa-zolium-5-olates and enamines (Scheme 63). Different enamine substitution pattern could lead to the corresponding pyrroles as single isomer. Furthermore, such a reaction could also be carried out from corresponding aldehydes in the presence of catalytic amount of secondary amine like $\mathrm{Bn}_{2} \mathrm{NH}$ or piperidine.

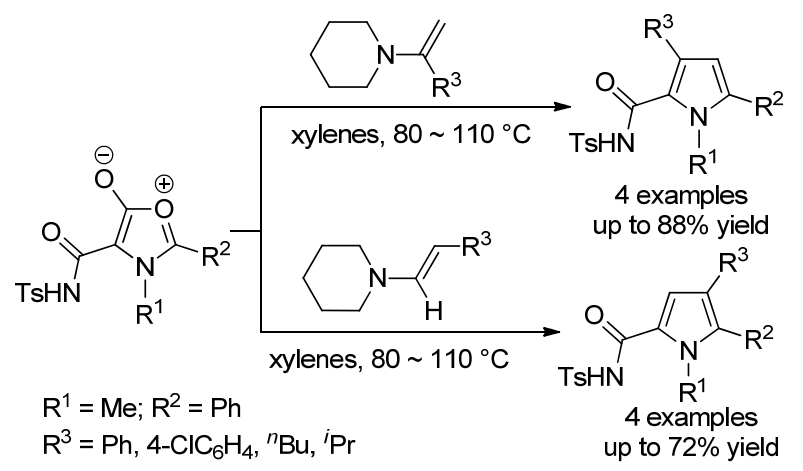

Scheme 63 Amine catalyzed cyclization between Münchnones and enamines

In 2015, Shi and co-workers ${ }^{[97]}$ disclosed a Rh-catalyzed cycloaddition of $2 \mathrm{H}$-azirines with $\mathrm{N}$-sulfonyl-1,2,3-triazoles to produce pyrroles via rhodium aza-vinyl carbene intermediates (Scheme 64). It was the first time for $N$-sulfonyl1,2,3-triazoles used as [C2] synthons in a formal cycloaddition reaction. This protocol was successful used to the total synthesis of URB447 and formal synthesis of

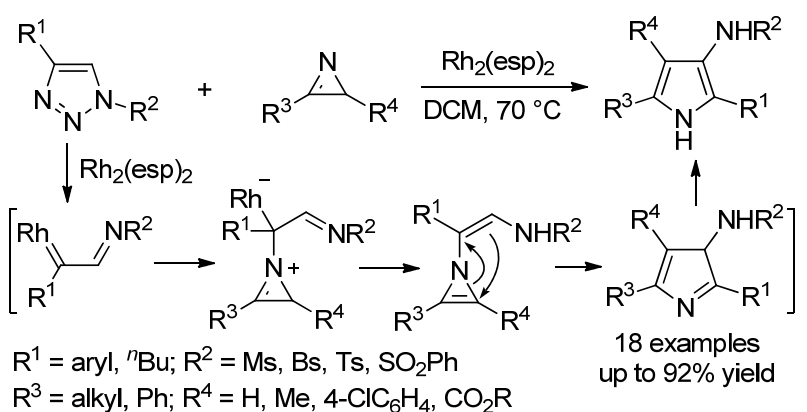

Scheme 64 Rhodium-catalyzed cycloaddition of $2 H$-azirines with $N$-sulfonyl-1,2,3-triazoles

Atorvastatin. Right after publication of this work, a very similar strategy was also reported by Tang group. ${ }^{[98]}$

A copper-catalyzed functionalization for the synthesis of substituted pyrroles was developed by Adimurthy and co-workers $^{[99]}$ using ketones and vinyl azides under mild conditions in the same year (Scheme 65). This protocol was a straightforward and efficient method to afford pyrroles in modest to excellent yields with broad functional group tolerance.

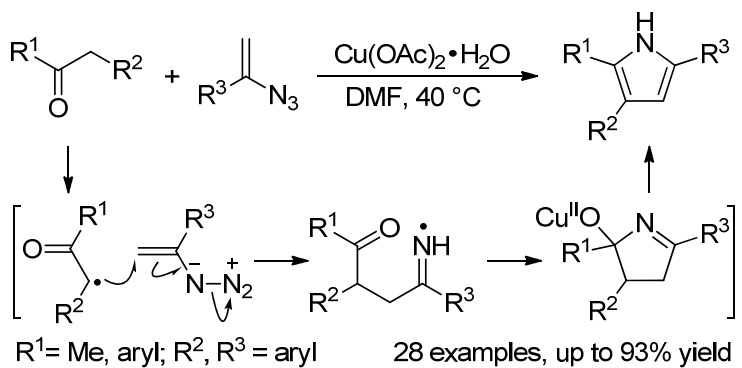

Scheme 65 Copper-catalyzed annulation between ketones and vinyl azides

Liu and co-workers ${ }^{[100]}$ also reported a gold-catalyzed cycloadditions between ynamides and vinyl azides or $2 \mathrm{H}$-azirines giving multisubtituted pyrroles (Scheme 66). In this formal $[3+2]$ cyclization procedure, the regioselectivity could be controlled by the use of a ester substituent on $2 \mathrm{H}$-azirine ring. Almost at the same time, similar strategy using vinyl azides has also been reported by Huang and co-workers. ${ }^{[101]}$

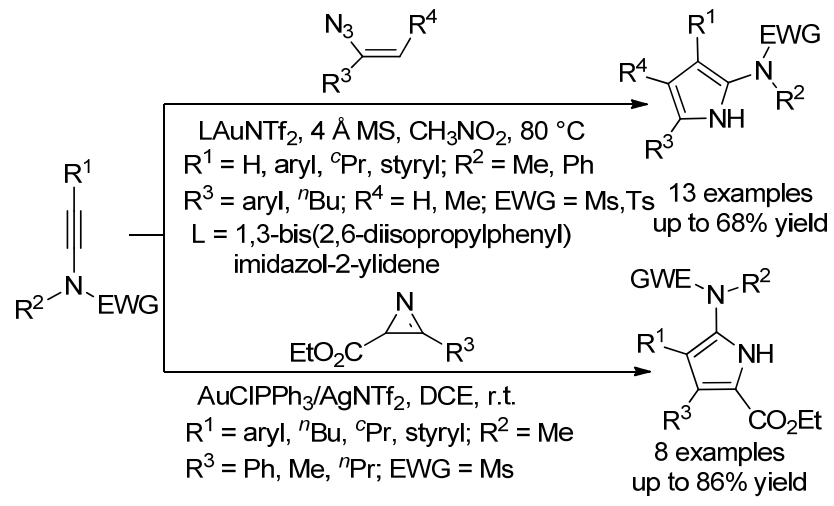

Scheme 66 Gold-catalyzed cycloadditions between ynamides and vinyl azides or $2 \mathrm{H}$-azirines

In 2018, a Fe(II)-catalyzed radical cycloaddition between $2 \mathrm{H}$-azirines and enamides yielding substituted pyrroles was described by Guan and co-workers (Scheme 67). ${ }^{[102]}$ The radical cycloaddition reaction generated 31 substituted pyrroles with up to $88 \%$ yield and good functional group tolerance.

\subsection{Cyclopropane and diazo type of substrate}

Cyclopropane and diazo compounds are important precursors for the construction of cyclic molecules, and have been used in the synthesis of pyrroles in recent years. In 2016, Gong and co-worker ${ }^{[103]}$ described an unexpected 


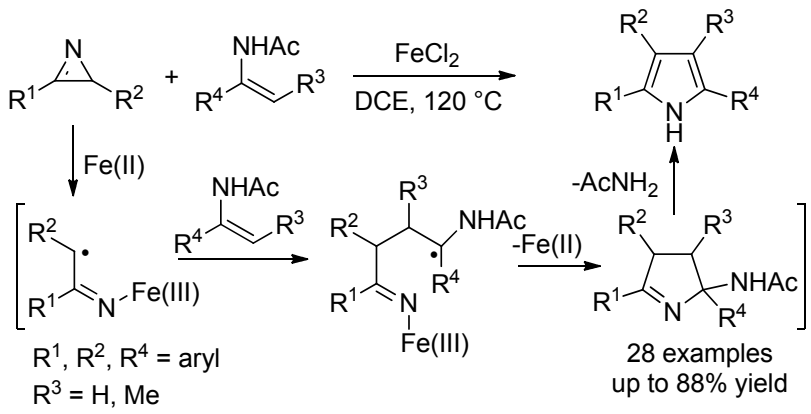

Scheme $67 \mathrm{Fe}(\mathrm{II})$-catalyzed cycloaddition of $2 H$-azirines and enamides

domino reaction between alkyl 2-aroyl-1-chlorocyclopropanecarboxylates and acylhy- drazono esters to afford 2,3,5-trifunctionalized pyrroles in the presence of $\mathrm{Cs}_{2} \mathrm{CO}_{3}$ (Scheme 68). The reaction could be carried out under mild basic conditions giving corresponding products with high regioselectivity.

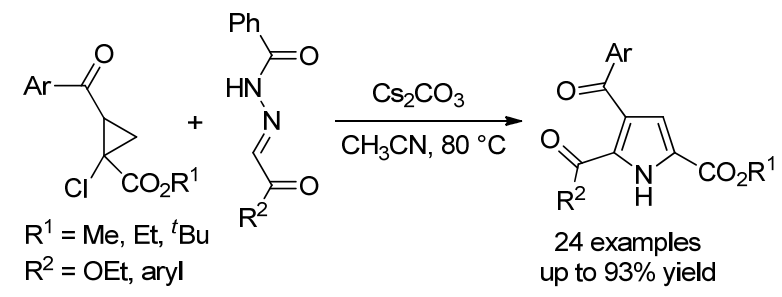

Scheme 68 Cesium-promoted reaction of alkyl 2-aroyl-1chlorocyclopropanecarboxylates and acylhydrazono esters

A three-component reaction of donor-acceptor cyclopropanes, salicylaldehydes and ammonium acetate in one-pot procedure was reported by Wang and co-workers ${ }^{[104]}$ giving substituted pyrrole in good yields (Scheme 69). Such a reaction went through a base-promoted cyclopropane ring-opening/nucleophilic addition to in situ generated imine intermediate/cyclization/isomerization process.

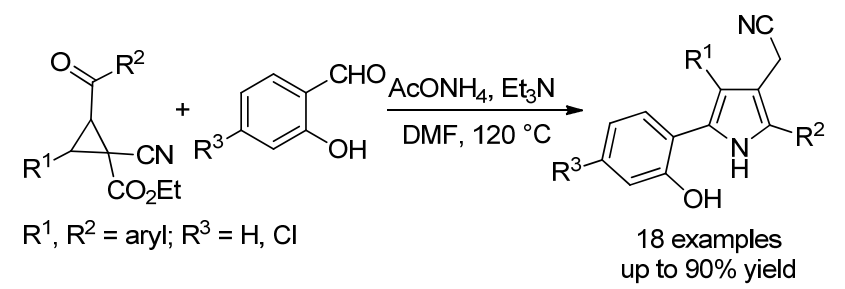

Scheme 69 Reaction of donor-acceptor cyclopropanes, salicylaldehydes and ammonium acetate

In 2015, during their investigation of heterocycle synthesis methods with ketimines through transition metal catalysis, Yoshikai and co-worker ${ }^{[105]}$ developed a copper-catalyzed regioselective condensation reaction between ketimines and $\alpha$-diazo- $\beta$-ketoesters producing multisubstituted pyrroles in moderate to good yields (Scheme 70). This reaction involves a nucleophilic addition/tautomerization/ cyclocondensation procedure, and features broad substrate scope and excellent functional group tolerance. Furthermore, its potential utility has been supported by the formal synthesis of lamellarins D and G.
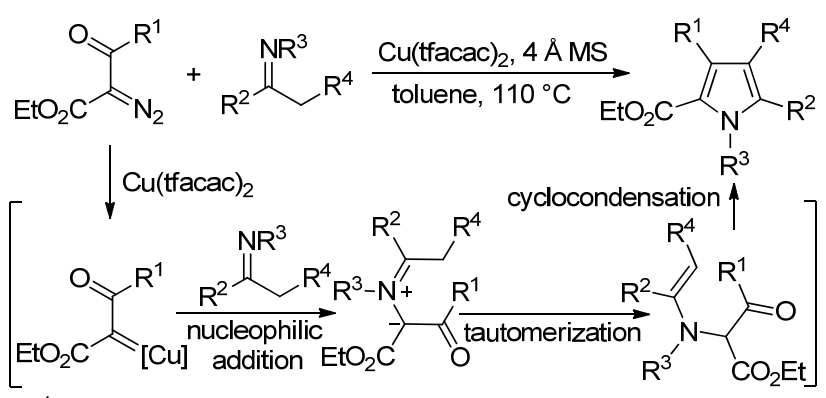

$\mathrm{R}^{1}=$ aryl, alkyl, $\mathrm{CO}_{2} \mathrm{Et}, \mathrm{H}, \mathrm{Ph}$, alkyl, acryl 44 examples $\mathrm{R}^{2}=$ aryl, alkyl; $\mathrm{R}^{3}=$ aryl, alkyl, allyl; $\mathrm{R}^{4}=\mathrm{H}, \mathrm{Me}, \mathrm{Ph}$ up to $94 \%$ yield

Scheme 70 Copper-catalyzed cyclization between ketimines and $\alpha$-diazo- $\beta$-ketoesters

Fischer carbene complexes are another important kind of precursors for pyrrole synthesis. In 2015, Vázquez and co-workers ${ }^{[106]}$ described a lithium diisopropylamid (LDA) promoted cascade reaction between alkynyl Fischer carbenes with $\alpha$-imino glycine methyl esters for the synthesis of 1,2,3,5-tetrasubstituted pyrroles (Scheme 71). This reaction proceeded through a 1,4-addition/isomerization/ring closure/demetalation cascade, which is different from the common 1,3-dipole cyclization mode for corresponding $\alpha$-imino glycine methyl esters.

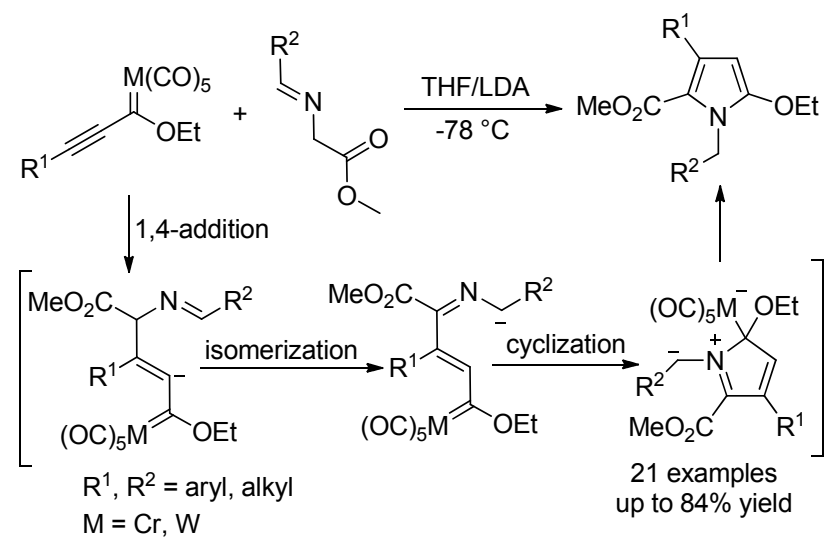

Scheme 71 LDA-promoted annulation between alkynyl Fischer carbenes with $\alpha$-imino glycine methyl esters

As an extension of their work in a diazo oxime etherbased pyrrole synthesis, Emmanuvel and co-workers ${ }^{[107]}$ reported a $\mathrm{Rh}$-catalyzed synthesis of $N$-alkoxy pyrroles via [3+2] cycloaddition between $\alpha$-diazo oxime with vinyl equivalents in 2017 (Scheme 72).

\section{$4[3+1+1]$ mode}

Frankly speaking, formal $[3+1+1]$ cyclization should be the least used mode for pyrrole synthesis.

In 2017, Mohammadi and co-workers ${ }^{[108]}$ reported a synthesis of pyrroles via a one-pot manner using arylidenmalononitrile, malononitrile and hydroxylamine hydrochloride as substrates (Scheme 73). Although the sub- 


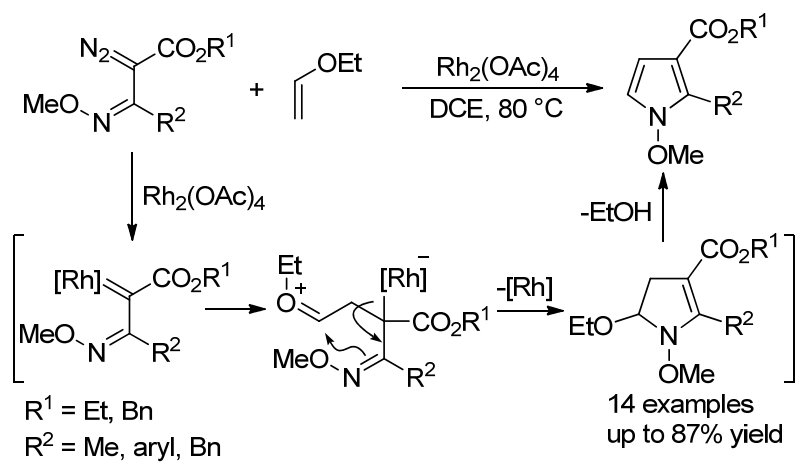

Scheme 72 Rh-catalyzed annulation between $\alpha$-diazo oxime with vinyl equivalents

strate scope is not excellent, this method still features the advantages of inexpensive starting material, short reaction times, and solvent-free conditions.

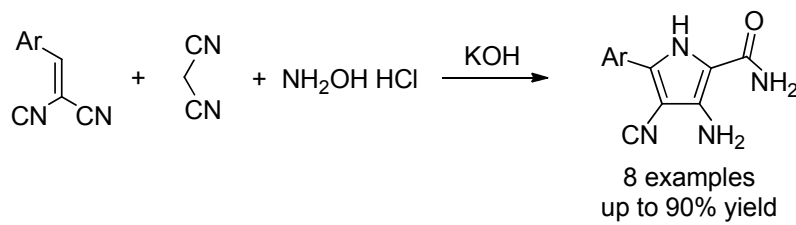

Scheme 73 Cyclization of arylidenmalononitrile, malononitrile and hydroxylamine hydrochloride

As part of their studies related to isocyanides, $\mathrm{Xu}$ and Tan et $a l .{ }^{[109]}$ developed a copper-catalyzed formal $[3+1+1]$ cyclization reaction between $\alpha$-acidic isocyanides and nitrone leading to polysubstituted pyrroles (Scheme 74). This method features operational simplicity, good functional group tolerance, and might provide new insights for isocyanide-related synthetic methodology development.

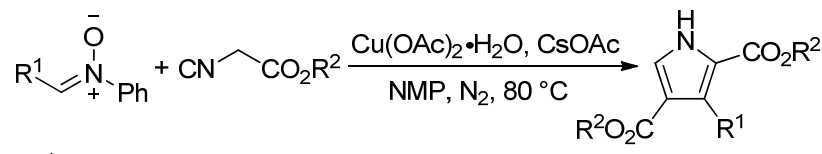

$$
\begin{aligned}
& \mathrm{R}^{1}=\text { aryl, alkyl } \\
& \mathrm{R}^{2}=\mathrm{Me}, \mathrm{Et},{ }^{t_{\mathrm{Bu}}} \\
& 26 \text { examples } \\
& \text { up to } 95 \% \text { yield }
\end{aligned}
$$

Scheme 74 Copper-catalyzed reaction between $\alpha$-acidic isocyanides and nitrone

\section{$5 \quad[2+2+1]$ mode}

The formal $[2+2+1]$ cycloaddition mode like the classic Hantzsch pyrrole synthesis is another important way for pyrrole synthesis. Since three units are involved, most of the methods are multicomponent reactions, which can be divided into two categories, i.e., $\mathrm{C} 2+\mathrm{C} 2+\mathrm{N} 1$ and $\mathrm{C} 2+$ $\mathrm{C} 1 \mathrm{~N} 1+\mathrm{C} 1$ versions.

\section{$5.1 \mathrm{C} 2+\mathrm{C} 2+\mathrm{N} 1$ version}

In the case of $\mathrm{C} 2+\mathrm{C} 2+\mathrm{N} 1$ version, two carbonyl compounds with one amine compound is one of the most common combination. Because stoichiometric amount of oxidant is normally needed for such a reaction pattern, developing new synthetic methods with simpler operational process and better sustainability is the main focus in recent years.

In 2015, during their study upon vicinal tricarbonyl type of compound, Doyle and co-workers ${ }^{[110]}$ reported a tandem aldol/cyclization/aromatization reaction of 2,3-diketoesters, ketones and amines using bezoic acid as the catalyst (Scheme 75). This reaction could produce 5-vinyl-pyrroles and 4-hydroxyindoles selectively by choosing monoketones and cyclohexane-1,3-diones as substrates, respectively. This metal-free process is consistent with green chemistry principles with water as byproduct and can be easily scaled up.

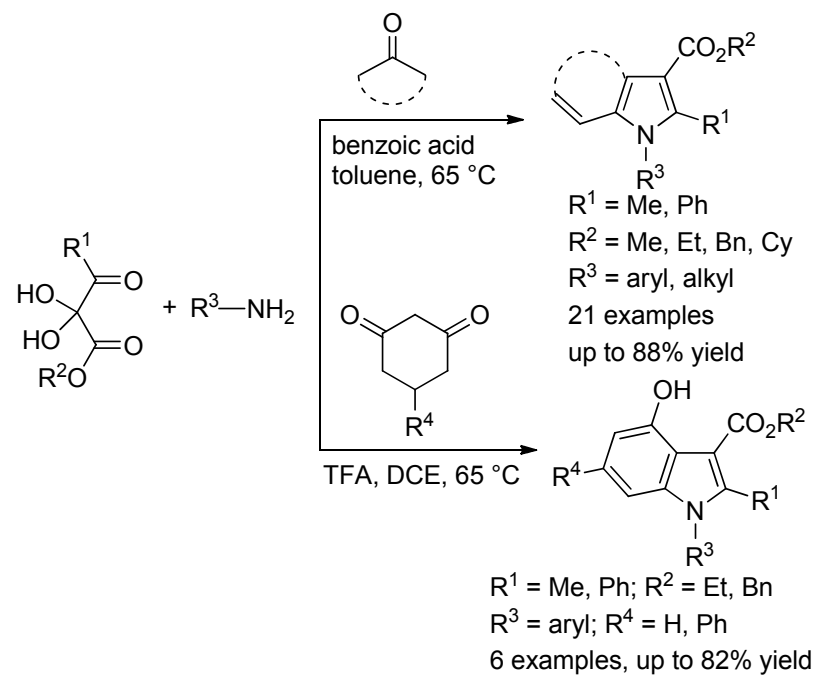

Scheme 75 Bezoic acid-promoted annulation of 2,3-diketoesters, ketones and amines

Using 1,2-diarylethan-1-ones and benzoins as the substrates, Lei and co-workers ${ }^{[111]}$ provided a cross-dehydrative aromatization for the generation of unsymmetrical tetraaryl-substituted pyrroles in 2016 (Scheme 76). Due to the presence of a hydroxyl group in benzoin substrate, an isomerization of the imine intermediate will give corresponding aminoketone intermediate for following coupling and cyclization transformations. Therefore, no extra oxidant was needed like similar strategies. This strategy could produce pyrroles in good to excellent yields through easy operation in acetic acid and ammonium acetate system.
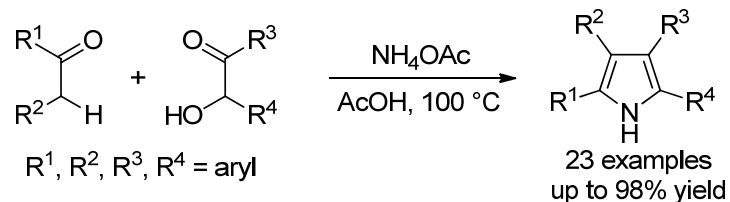

Scheme 76 Cyclization of 1,2-diarylethan-1-ones and benzoins

In 2019, during their pursuit of a more environmentally friendly strategy to construct pyrrole skeleton, the same team also developed a practical protocol to synthesize polysubstituted pyrroles via electrooxidative annulation between amines and aldehydes or ketones (Scheme 77). ${ }^{[12]}$ 
Although corresponding imine intermediates should be prepared before the key annulation, this protocol presents good functional group tolerance and scalability under mild conditions.

$$
\begin{aligned}
& \underset{\mathrm{NaOAc}, \mathrm{THF}}{\mathrm{C}(+) \mathrm{Pt}(-)} \\
& \mathrm{R}^{1} \mathrm{O} \quad \mathrm{R}^{1}=\mathrm{H} ; \mathrm{R}^{2}=\text { aryl; } \mathrm{R}^{3}=\text { alkyl, aryl, } \mathrm{Bn} \\
& \mathrm{R}^{2}+\mathrm{R}^{3}-\mathrm{NH}_{2}-28 \text { examples, up to } 74 \% \text { yield } \\
& \underset{\text { dry } \mathrm{MeOH} \mathrm{NaOAc}, \mathrm{THF}_{\mathrm{R}^{1}}}{\stackrel{\mathrm{A} \mathrm{MS}}{\mathrm{C}(+) \mathrm{Pt}(-)}} \\
& \mathrm{R}^{1}=\mathrm{H} \text {, alkyl, aryl, } \mathrm{CO}_{2} \mathrm{Me} \\
& \mathrm{R}^{2}=\text { alkyl, aryl, } \mathrm{Bn} ; \mathrm{R}^{3}={ }^{n} \mathrm{Bu} \\
& 11 \text { examples, up to } 56 \% \text { yield }
\end{aligned}
$$

Scheme 77 Electrooxidative annulation between amines and aldehydes or ketones

Following the seminal work of Jia, ${ }^{[113]}$ Deng, Huang and co-workers ${ }^{[114]}$ described a copper-catalyzed aerobic system of alkylamines and aromatic acetaldehydes to give substituted pyrroles in good to excellent yields (Scheme 78). This facile ambient method presented advantages of mild conditions and high atom-economy. In particular, the use of copper catalyst, such a cyclization could go through smoothly with oxygen as the oxidant.
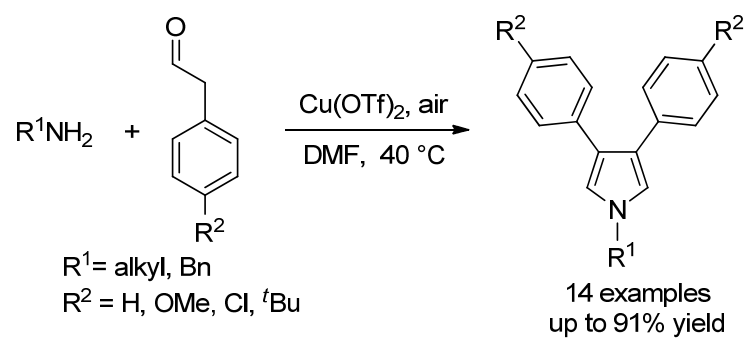

Scheme 78 Copper-catalyzed annulation of alkylamines and aromatic acetaldehydes

Other than the carbonyl compound itself, its surrogate or synthetic precursor has also been used as substrate for $\mathrm{C} 2+$ $\mathrm{C} 2+\mathrm{N} 1$ version. One typical precursor is renewable alcohol, which could be transformed into corresponding carbonyl compound through the dehydrogenation reaction in the presence of proper metal catalyst. Ideally, if such a catalyst is also suitable for subsequent cyclization, a proper synthetic will be developed. In 2017, Seayad and co-workers ${ }^{[115]}$ reported a $[\mathrm{Cu}(\mathrm{NHC})]$-catalyzed threecomponent coupling reaction of ketone, primary amine and diol for the syntheses of substituted pyrroles (Scheme 79). However, the regioselectivity of this cyclization for diol substrate was not investigated.

Using the same strategy, El-Sepelgy, Rueping and Cavallo et al. ${ }^{[116]}$ described a manganese-catalyzed synthesis of pyrroles through the cyclization of ketones, amine,

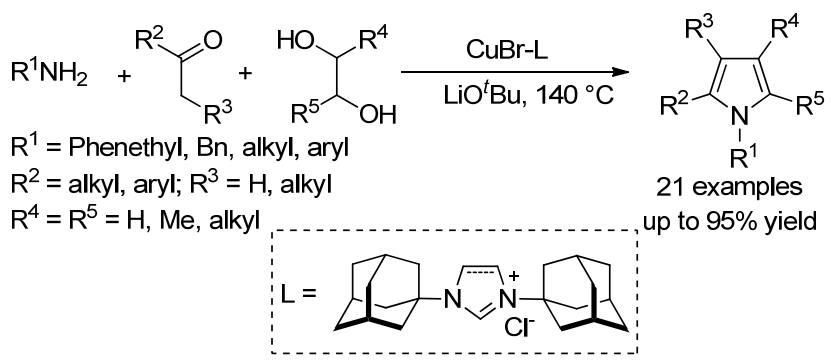

Scheme $79[\mathrm{Cu}(\mathrm{NHC})]$-catalyzed cyclization of ketone, primary amine and diol

and diols in good yields (Scheme 80). This heterocondensation cascade could be utilized under the air- and moisture-stable catalyst system with water and hydrogen gas as the byproducts. And for diol substrates with different substituents $\left(\mathrm{R}^{3} \neq \mathrm{R}^{4}\right)$, the reaction also showed good regioselectivity. Notably, it is the first report that proves the involving of both acceptorless dehydrogenation and hydrogen autotransfer processes in heterocycle synthesis.

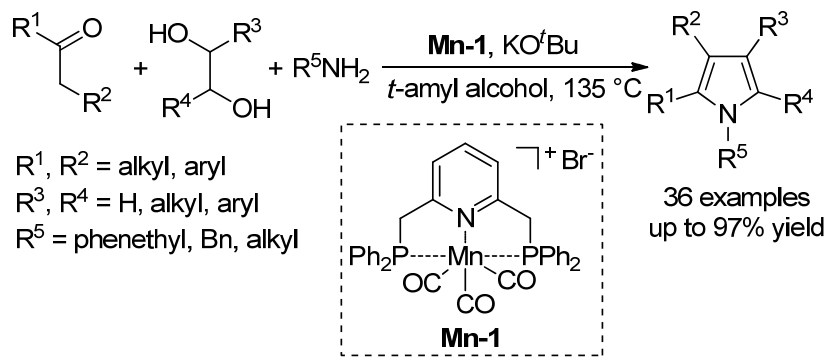

Scheme 80 Manganese-catalyzed cyclization of ketones, amine, and diols

Applying silylenolate as the surrogate of carbonyl compound, Kartika and co-workers ${ }^{[117]}$ developed a Brønsted acid catalyzed expedient annulation reaction of two silylenolates and primary amines affording tetrahydroindole and tetrahydrocyclopenta $[b]$ pyrrole derivatives (Scheme 81 ). Such a one-pot reaction was initiated by the formation of corresponding silyloxyallyl cations followed by consecutive nucleophilic coupling with another silylenolate and Paal-Knorr type of cyclization with primary amine to give the final pyrrole compound.

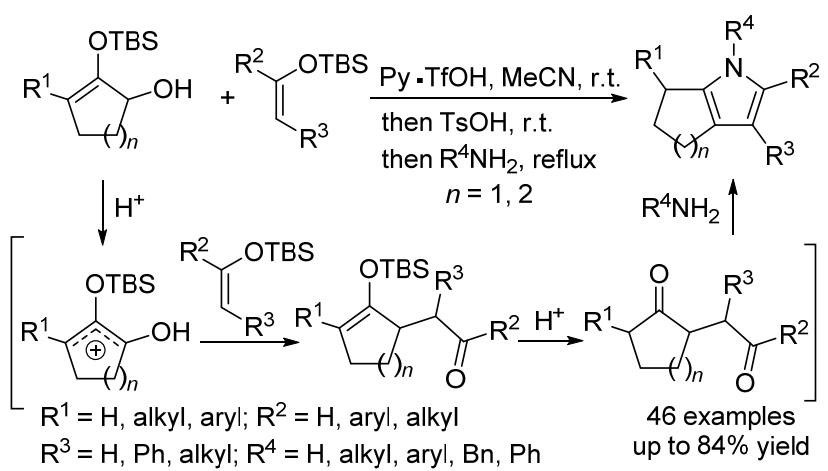

Scheme 81 Brønsted acid catalyzed annulation of silylenolates and primary amines 
Inspired by the coupling reaction between alkenes and ketones for the synthesis of 1,4-dicarbonyl compounds, Gong and co-workers ${ }^{[118]}$ developed a one-pot copper/ manganese co-catalyzed reaction to produce 1,2,5-trisubstituted pyrroles from styrenes, acetone and arylamines in the presence of $t$-butyl hydroperoxide (TBHP), trifluoromethanesulfonate and sulfamic acid (Scheme 82).

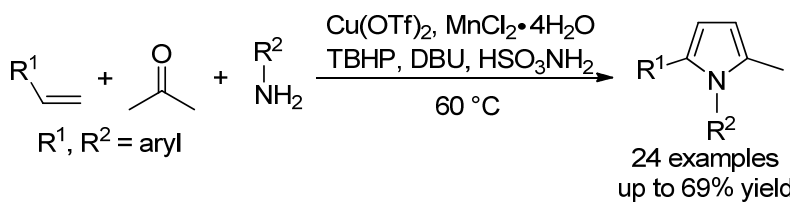

Scheme 82 Copper/manganese co-catalyzed reaction between styrenes, acetone and arylamines

Besides carbonyl type of compound, alkenes or alkynes are also used as the $\mathrm{C} 2$ units for pyrrole synthesis via $[2+$ $2+1]$ mode.

In 2016, Tonks and co-workers ${ }^{[119]}$ reported a Ti-catalyzed tandem reaction for the synthesis of multisubstituted pyrroles from alkynes and diazenes (Scheme 83). This procedure was one special example of catalytic oxidative formal $[2+2+1]$ six-electron cyclization with a key feature of the cleavage of $\mathrm{N}=\mathrm{N}$ double bond in an aryl diazene. However, in the case of unsymmetrical alkynes, the regioselectivity of such a cyclization is not satisfactory.
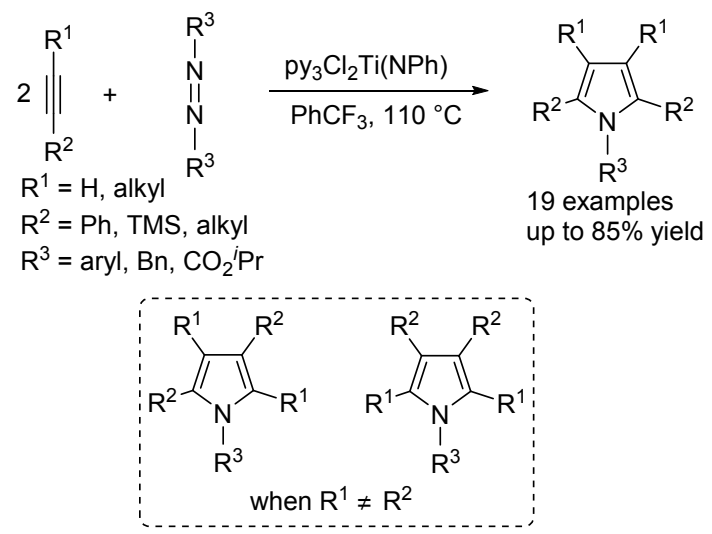

Scheme 83 Ti-catalyzed cyclization between alkynes and diazenes

Later on, after extensive substrate investigation, the same team successfully improved the chemo- and regioselectivity of above tandem reaction by using silyl-substituted alkynes with/without the assistance of a Lewis basic dative directing group (Scheme 84). ${ }^{[120]}$ Accordingly, a number of highly substituted pyrroles with a silyl substituent could be obtained with high chemo- and region-selectivities. Meanwhile, the existence of a silyl group paves way for further derivatization.

In 2018 , the same team also developed a formal $[2+2+$ 1] coupling for synthesis of polysubstituted pyrroles from azides and alkynes via $\mathrm{Ti}(\mathrm{II}) / \mathrm{Ti}(\mathrm{IV})$ redox catalysis with good yields (Scheme 85). ${ }^{[121]}$

The introduction of proper activating groups is also an

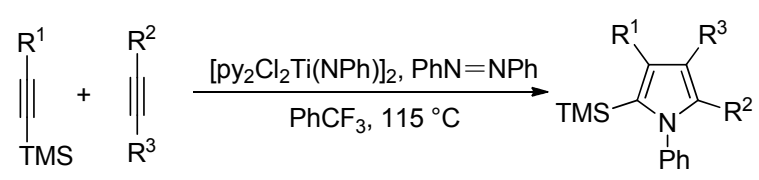

$\mathrm{R}^{1}=\mathrm{H}, \mathrm{TMS}$, alkyl, aryl, vinyl

$\mathrm{R}^{2}, \mathrm{R}^{3}=$ aryl, alkyl

$>50$ examples up to $92 \%$ yield up to $99 \%$ chemo- \& regio-selectivity

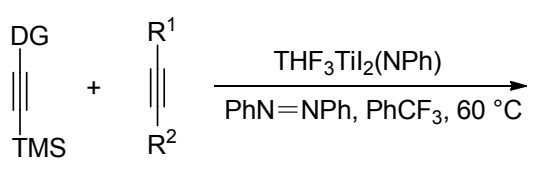

$D G=$ Lewis basic dative directing group $\mathrm{R}^{1}=\mathrm{Me} ; \mathrm{R}^{2}=\mathrm{Ph}$

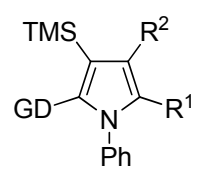

7 examples up to $76 \%$ yield up to $>95 \%$ chemo- \&

regio-selectivity
Scheme 84 Ti-catalyzed annulation of alkynes with phenyl diazene

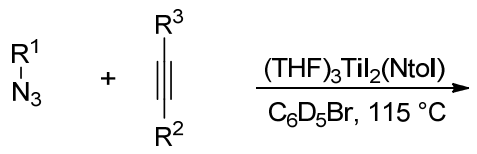

$\mathrm{R}^{1}=\mathrm{Ad}$, tol, $\mathrm{Bn},{ }^{n} \mathrm{Dec}$

$\mathrm{R}^{2}, \mathrm{R}^{3}=$ aryl, $\mathrm{Ph}, \mathrm{H}$, tol, TMS<smiles>[R]c1c([R])c([R])n([R])c1[R]</smiles>

14 examples up to $94 \%$ yield
Scheme $85 \mathrm{Ti}(\mathrm{II}) / \mathrm{Ti}(\mathrm{IV})$ redox-promoted reaction between azides and alkynes

alternative way to increase the reactivity of alkyne or alkene moiety. One benefit of such a strategy is that better regioselectivity is usually relatively easier to realize. In 2016, $\mathrm{Yi}$ and co-workers ${ }^{[122]}$ disclosed a Pd(II)-catalyzed oxidative cascade reaction for the regioselective synthesis of 1,2,3,4-tetrasubstituted pyrroles from amines, alkyne esters, and alkenes (Scheme 86). Due to the used of alkyne esters, corresponding enamine could be regioselectively generated in situ and coupled with styrene type of alkene to give the key intermediate, which would be converted to final pyrrole through cyclization/aromatization. Using similar type of strategy, Zhang and co-workers ${ }^{[123]}$ described a facile $\mathrm{Mn}(\mathrm{OAc})_{3}$-promoted oxidative cyclization reaction of alkenes, amines and alkyne esters to form 2,3-dihydropyrroles.

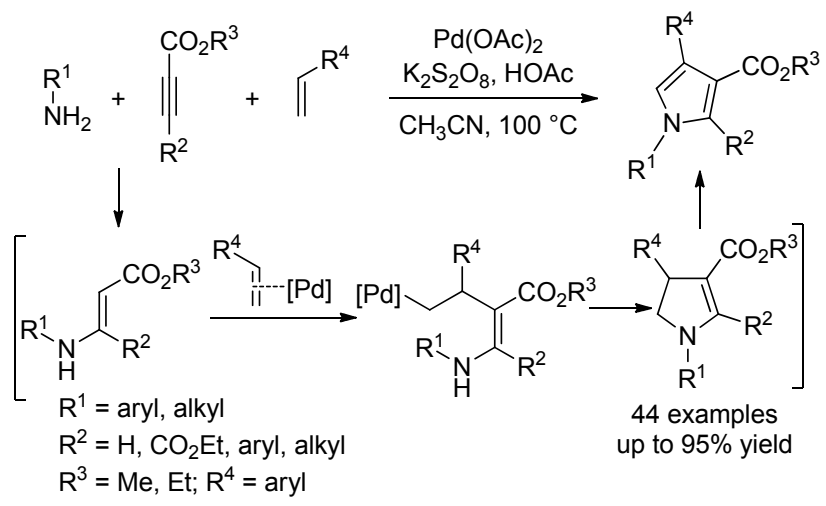

Scheme 86 Pd(II)-promoted cyclization of amines, alkyne esters, and alkenes 
Changing the substrate combination to primary amine, $\alpha$-nitroepoxide and dialkyl acetylenedicarboxylate, $\mathrm{Yu}$ and Zhang et al. ${ }^{[124]}$ developed a facile reaction to synthesize penta-substituted pyrroles under simple heating condition in seal tube (Scheme 87). This reaction went through an interesting epoxide ring opening denitro process to form amino ketone intermediate, which reacted with dialkyl acetylenedicarboxylate through an $a z a$-Michael/aldol/ dehydration cascade to give final pyrrole product.

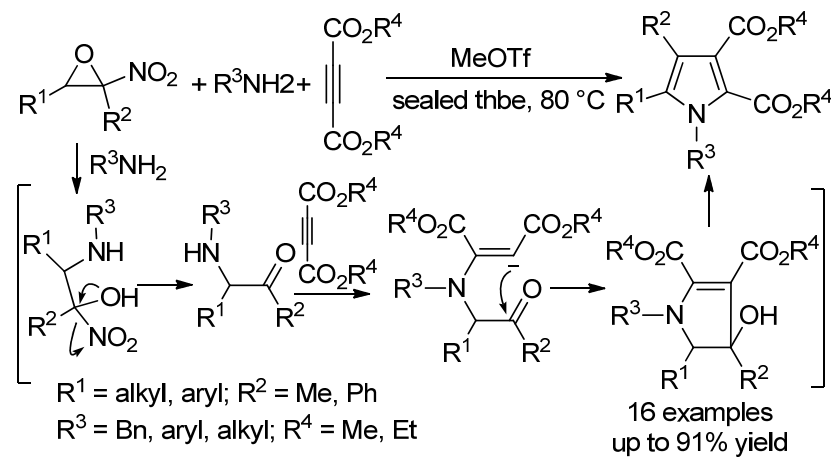

Scheme 87 Cyclization of primary amine, $\alpha$-nitroepoxide and dialkyl acetylenedicarboxylate

Based on similar strategy, the same team ${ }^{[125]}$ demonstrated a multi-component reaction of $\alpha$-nitroepoxides, amines and malononitrile to produce 2-amino-3-cyanopyrroles in the presence of $\mathrm{K}_{2} \mathrm{CO}_{3}$ (Scheme 88).

$$
\begin{aligned}
& \mathrm{R}^{1}={ }^{n} \mathrm{Pr} \text {, aryl; } \mathrm{R}^{2}=\mathrm{Me}, \mathrm{Et} \\
& \mathrm{R}^{3}=\operatorname{aryl} \text {, alkyl }
\end{aligned}
$$

Scheme $88 \quad \mathrm{~K}_{2} \mathrm{CO}_{3}$-mediated annulation of $\alpha$-nitro epoxides, amines and malononitrile

In 2015, Nair and co-workers ${ }^{[126]}$ reported a zirconocene dichloride catalyzed cyclization for the synthesis of multisubstituted pyrroles from amines, nitroalkenes and $\beta$-dicarbonyl compounds (Scheme 89). The one-pot reaction could proceed easily in ethanol medium with high yields and no side products, and provided an alternative choice for related methods under environmentally benign conditions.

$$
\begin{aligned}
& \mathrm{R}^{1} \\
& \mathrm{NH}_{2} \\
& \mathrm{R}^{1}=\mathrm{O}=\mathrm{O} \mathrm{R}^{3} \mathrm{O}, \mathrm{Bn} ; \mathrm{R}^{2}=\mathrm{Me}, \mathrm{Ph},{ }^{i} \mathrm{Pr} \\
& \mathrm{R}^{3}=\mathrm{Me}, \text { arylamino, ethoxy; } \mathrm{R}^{4}=\text { aryl } \\
& \mathrm{R}^{5}=\mathrm{H}, \mathrm{Me} \text {, aryl }
\end{aligned}
$$

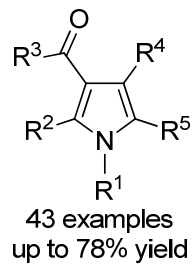

Scheme 89 Zirconocene dichloride-catalyzed cyclization of amines, nitroalkenes, and $\beta$-dicarbonyl compounds

\section{$5.2 \mathrm{C} 2+\mathrm{C} 1 \mathrm{~N} 1+\mathrm{C} 1$ Version}

For such a version, nitrile and isocyanide are usually chosen as C1N1 unit. In the case of nitrile as a C1N1 unit, $\mathrm{Xi}$ and co-workers ${ }^{[127]}$ developed a multicomponent domino reaction for the synthesis of 2,3,4,5-tetrasubstituted pyrroles from alkylnitriles, arylalkynes and MeOTf under metal-free conditions (Scheme 90). As an extension of their study on alkyltriflatemediated annulation, this reaction was also initiated by the electrophilic addition of MeOTf to arylnitrile giving nitrilium intermediate, which reacted with alkyne to provide alkenyl carbocation intermediate. The corresponding alkenyl carbocation intermediate would go through a 1,5-H shift/annulation/elimination/isomerization to afford pyrrole intermediate, which reacted with another nitrilium intermediate to give final pyrrole product upon work up. This synthesis strategy showed high regioselectivity with moderate to good yields. Additionally, the use of diarylalkynes with electron-rich aryl groups would produce isoquinolines instead.

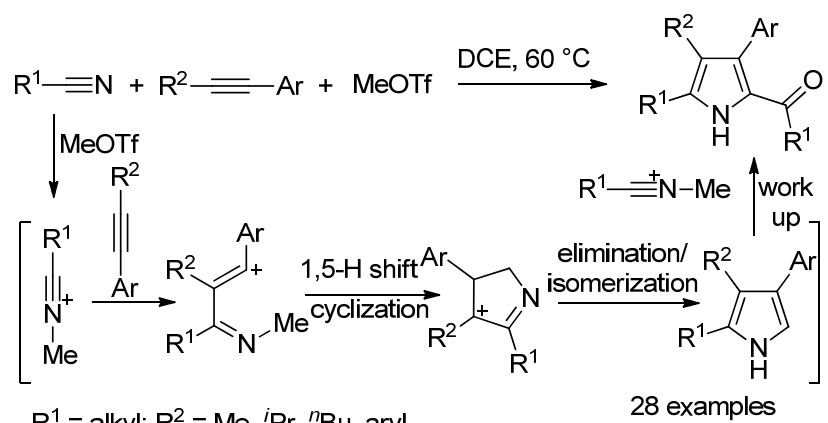

$\mathrm{R}^{1}=$ alkyl; $\mathrm{R}^{2}=\mathrm{Me},{ }^{i} \mathrm{Pr},{ }^{n} \mathrm{Bu}$, aryl

up to $78 \%$ yield

Scheme 90 Cyclization of alkylnitriles, arylalkynes and MeOTf

Using isocyanide as $\mathrm{C} 1 \mathrm{~N} 1$ unit, Jiang and $\mathrm{Wu}$ et al. ${ }^{[128]}$ reported a palladium-catalyzed multicomponent reaction for the synthesis of pyrrole derivatives from propargylic carbonates and isocyanides (Scheme 91). This reaction
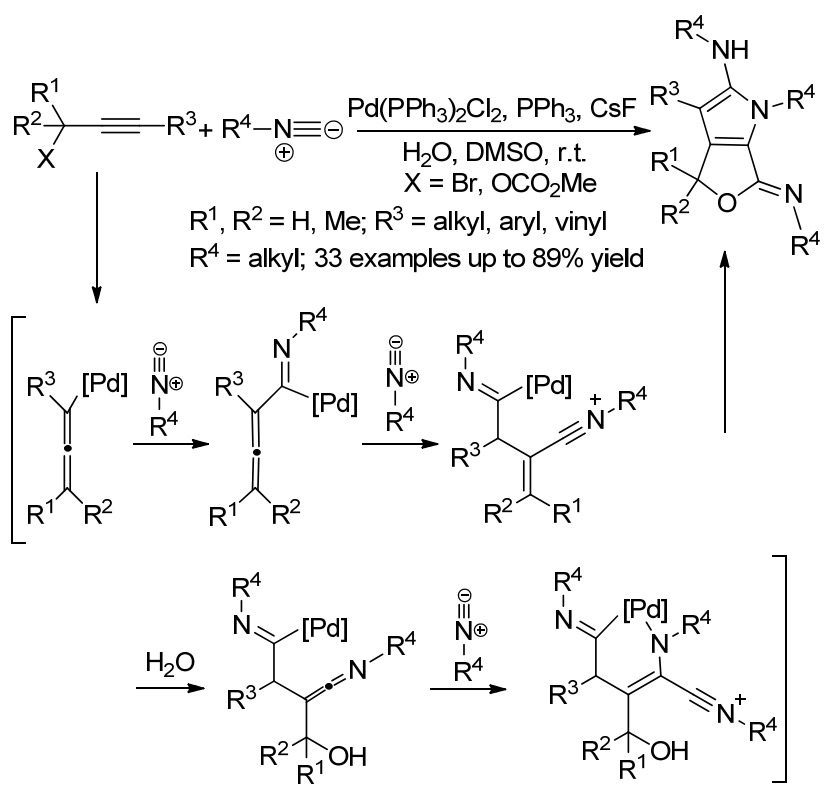

Scheme 91 Palladium-promoted cyclization between propargylic carbonates and isocyanides 
started with the formation of allene intermediate, which went through isocyanide insertion and three consecutive addition steps to produce key intermediate for final cyclization. Then a reductive elimination and subsequent aromatization would give pyrrole product. Meanwhile, the method could selectivity produce pyrrolone derivatives by choosing different ligand and reaction temperature.

Almost at the same time, Zhu and Wang ${ }^{[129]}$ also developed a Pd-catalyzed multicomponent reactions to produce polysubstituted pyrroles via a very similar mechanism (Scheme 92). Using two different protic reagents, two types of pyrrole skeletons could be obtained.

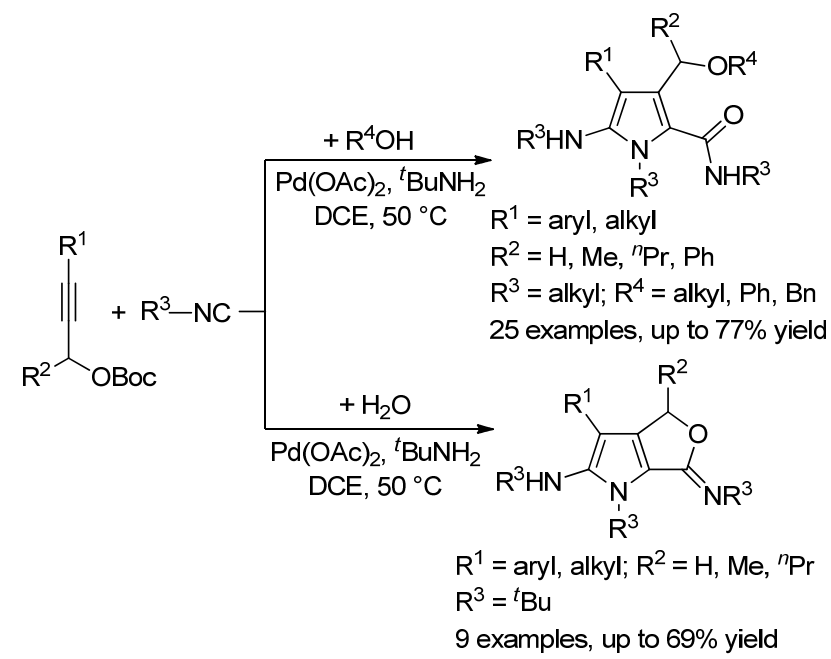

Scheme 92 Pd-catalyzed reactions of propargyl carbonates, isocyanides, and alcohols or water

In 2017, Jiang, Wu and co-workers ${ }^{[130]}$ further developed a palladium-catalyzed approach for synthesis of multisubstituted 3-amino pyrroles via three-component tandem reaction (Scheme 93). This reaction was initiated with a double isocyanide insertions of a Pd complex generated by $\mathrm{Pd}$ catalyst and halide substrates. Next, a formal carbonpalladium insertion of diazo intermediate derived from $N$-tosylhydrazone substrate followed by $\beta$-hydrogen elimination/cyclization/aromatization process to produce final pyrrole product. Such a procedure showed advantages of

$$
\begin{aligned}
& \mathrm{R}_{1}^{\mathrm{R}^{1}}+\underset{\Theta}{\mathrm{R}^{2}-\mathrm{N} \equiv \Theta} \\
& \mathrm{R}^{1}=\text { aryl, styryl, phenylethynyl } \\
& \mathrm{R}^{2}=\text { alkyl; } \mathrm{R}^{3}=\text { aryl }
\end{aligned}
$$

Scheme 93 Palladium-promoted annulation of aryl halides, $N$-tosylhydrazones, and isocyanides readily starting materials, high assembly efficiency, and good functional group tolerance under mild reaction conditions.

\section{Conclusions}

After the continuous efforts of synthetic chemists, the development of methodologies for pyrrole construction has made great progress. Due to the importance of pyrrole skeleton, even in the past five years, a number of new methods have been reported. Especially, under the promotion of sustainable development and ideal synthesis, the use of basic raw chemical and green inexpensive catalyst has received considerable interests. It also should be noted that the discovery of new functional molecules based on above synthetic methods is still underdeveloped. Aiming to the development of novel pyrrole-based functional molecules via environmentally friendly and economically efficient synthetic methods, we hope this review could give some insights for researchers in related field.

\section{References}

[1] Gribble, G. W. In Comprehensive Heterocyclic Chemistry II, Pergamon Press, Oxford, 1996, p. 207.

[2] Jones, R. A. Pyrroles: The Synthesis and the Physical and Chemical Aspects of the Pyrrole Ring, John Wiley \& Son, New York, 1990.

[3] Mal, D.; Shome, B.; Dinda, B. K. Pyrrole and Its Derivatives in Heterocycles in Natural Product Synthesis, Germany, Mal, D.; Shome, B.; Dinda, B. K. Pyrrole and Its Derivatives in Heterocycles in Natural Product Synthesis, Germany, Wiley-VCH Verlag 2011, Chapter 6.

[4] Bergman, J.; Janosik, T. In Five-Membered Heterocycles: Pyrrole and Related Systems in Modern Heterocyclic Chemistry, Wiley VCH Verlag GmbH \& Co. KGaA, Weinheim, Germany, 2011, Chapter 4.

[5] Eicher, T. J. Prakt. Chem./Chem.-Ztg. 1998, 340, 487.

[6] Boger, D. L.; Boyce, C. W.; Labroli, M. A.; Sehon, C. A.; Jin, Q. J. Am. Chem. Soc. 1999, 121, 54.

[7] Furstner, A.; Weintritt, H. J. Am. Chem. Soc. 1998, 120, 2817.

[8] Liu, J. H.; Yang, Q. C.; Mak, T. C. W.; Wong, H. N. C. J. Org. Chem. 2000, 65, 3587.

[9] Walsh, C. T.; Garneau-Tsodikova, S.; Howard-Jones, A. R. Nat. Prod. Rep. 2006, 23, 517.

[10] Wang, X.; Ma, Z.; Wang, X.; De, S.; Ma, Y.; Chen, C. Chem. Commun. 2014, 50, 8628.

[11] Huang, X. C.; Xiao, X.; Zhang, Y. K.; Talele, T. T.; Salim, A. A.; Chen, Z. S.; Capon, R. J. Mar. Drugs 2014, 12, 3818.

[12] Hayakawa, Y.; Kawakami, K.; Seto, H. Tetrahedron Lett. 1992, 33, 2701.

[13] Han, W. B.; Lu, Y. H.; Zhang, A. H.; Zhang, G. F.; Mei, Y. N.; Jiang, N.; Lei, X.; Song, Y. C.; Ng, S. W.; Tan, R. X. Org. Lett. 2014, 16, 5366.

[14] Kinnel, R. B.; Gehrken, H. P.; Scheuer, P. J. J. Am. Chem. Soc. 1993, $115,3376$.

[15] Nishimura, S.; Matsunaga, S.; Shibazaki, M.; Suzuki, K.; Furihata, K.; Soest, R. W. M. V.; Fusetani, N. Org. Lett. 2003, 5, 2255.

[16] Munoz, J.; Köck, M. J. Nat. Prod. 2016, 79, 434

[17] Han, W. B.; Zhang, A. H.; Deng, X. Z.; Lei, X.; Tan, R. X. Org. Lett. 2016, 18, 1816.

[18] Lv, H. N.; Zeng, K. W.; Zhao, M. B.; Jiang, Y.; Tu, P. F. J. Asian Nat. Prod. Res. 2018, 20, 195.

[19] Zhang, F.; Braun, D. R.; Chanana, S.; Rajski, S. R.; Bugni, T. S. J. Nat. Prod. 2019, 82, 3432 .

[20] Lee, Y. J.; Kim, S. H.; Choi, H.; Lee, H. S.; Lee, J. S.; Shin, H. J.; 
Lee, J. Molecules 2019, 24, 840

[21] (a) Estévez, V.; Villacampa, M.; Menéndez, J. C. Chem. Soc. Rev. 2014, 43, 4633.

(b) Yoshikai, N.; Wei, Y. Asian J. Org. Chem. 2013, 2, 466.

(c) Ono, N. Heterocycles 2008, 75, 243.

(d) Schmuck, C.; Rupprecht, D. Synthesis 2007, 39, 3095.

(e) Ferreira, V. F.; De Souza, M. C. B. V.; Cunha, A. C.; Pereira, L.

O. R.; Ferreira, M. L. G. Org. Prep. Proced. Int. 2001, 33, 411.

[22] (a) Leonardi, M.; Estevez, V.; Villacampa, M.; Menendez, J. C.; Synthesis 2019, 51, 816 .

(b) Balakrishna, A.; Aguiar, A.; Sobral, P. J. M.; Wani, M. Y.; Almeida e Silva, J.; Sobral, A. J. F. N. Catal. Rev. 2019, 61, 84.

(c) Ma, Z.; Ma, Z.; Zhang, D. Molecule 2018, 23, 2666.

(d) Azad, I.; Hassan, F.; Saquib, M.; Ahmad, N.; Rahman Khan, A.;

Al-Sehemi, A. G.; Nasibullah, M. Orient. J. Chem. 2018, 34, 1670.

(e) Vessally, E. RSC Adv. 2016, 6, 18619.

(f) Bhardwaj, V.; Gumber, D.; Abbot, V.; Dhiman, S.; Sharma, P. RSC Adv. 2015, 5, 15233.

(g) Olivier, W. J.; Smith, J. A.; Bissember, A. C. Org. Biomol. Chem. 2018, 16, 1216.

(h) Sharma, A.; Piplani, P. J. Heterocycl. Chem. 2017, 54, 27.

[23] Galenko, E. E.; Bodunov, V. A.; Galenko, A. V.; Novikov, M. S.; Khlebnikov, A. F. J. Org. Chem. 2017, 82, 8568.

[24] Yasukawa, N.; Kuwata, M.; Imai, T.; Monguchi, Y.; Sajiki, H.; Sawama, Y. Green Chem. 2018, 20, 4409.

[25] Rajesh, M.; Puri, S.; Kant, R.; Reddy, M. S. Org. Lett. 2016, 18, 4332.

[26] Qi, Z.; Jiang, Y.; Wang, Y.; Yan, R. J. Org. Chem. 2018, 83, 8636.

[27] Shen, M. H.; Ren, X. T.; Pan, Y. P.; Xu, H. D. Org. Chem. Front. 2018, 5,46

[28] Wu, F.; Chen, L.; Wang, Y.; Zhu, S. Org. Chem. Front. 2019, 6, 480.

[29] Undeela, S.; Thadkapally, S.; Nanubolu, J. B.; Singarapu, K. K.; Menon, R. S. Chem. Commun. 2015, 51, 13748.

[30] Zhao, Y.; Wang, H.; Li, X.; Wang, D.; Xin, X.; Wan, B. Org. Biomol. Chem. 2016, 14, 526.

[31] Yang, X.; Wang, Y.; Hu, F.; Kan, X.; Yang, C.; Liu, J.; Liu, P.; Zhang, Q. RSC Adv. 2016, 6, 68454.

[32] Shen, J.; Yang, X.; Wang, F.; Wang, Y.; Cheng, G.; Cui, X. RSC Adv. 2016, 6, 48905 .

[33] Ge, B.; Lv, W.; Yu, J.; Xiao, S.; Cheng, G. Org. Chem. Front. 2018 , 5,3103 .

[34] Gillbard, S. M.; Chung, C. H.; Karad, S. N.; Panchal, H.; Lewis, W.; Lam, H. W. Chem. Commun. 2018, 54, 11769.

[35] Shen, W.-B.; Zhou, B.; Zhang, Z.-X.; Yuan, H.; Fang, W.; Ye, L.-W. Org. Chem. Front. 2018, 5, 2468.

[36] Meng, L.; Chi, X.; Sun, X.; Cao, C.; Ai, B.; Liu, Q.; Zhao, P.; Zhao, Z.; Dong, Y.; Liu, H. Org. Biomol. Chem. 2019, 17, 7669.

[37] Pan, D.; Wei, Y.; Shi, M. Org. Lett. 2016, 18, 3930.

[38] Zhang, C.; Chang, S.; Qiu, L.; Xu, X. Chem. Commun. 2016, 52, 12470.

[39] Jiang, Y. J.; Chan, W. C.; Park, C. M. J. Am. Chem. Soc. 2012, 134, 4104

[40] Xu, X. M.; Lei, C. H.; Tong, S.; Zhu, J.; Wang, M. X. Org. Chem. Front. 2018, 5, 3138.

[41] Karimi, S.; Ma, S.; Liu, Y.; Ramig, K.; Greer, E. M.; Kwon, K.; Berkowitz, W. F.; Subramaniam, G. Tetrahedron Lett. 2017, 58, 2223.

[42] Daw, P.; Chakraborty, S.; Garg, J. A.; David, Y. B.; Milstein, D. Angew. Chem., Int. Ed. 2016, 55, 14373.

[43] Singh, K.; Kabadwal, L. M.; Bera, S.; Alanthadka, A.; Banerjee, D. J. Org. Chem. 2018, 83, 15406.

[44] (a) Mou, X. Q.; Xu, Z. L.; Wang, S. H.; Zhu, D. Y.; Wang, J.; Bao, W.; Zhou, S. J.; Yang, C.; Zhang, D. Chem. Commun. 2015, 51, 12064.

(b) Xu, X. T.; Mou, X. Q.; Xi, Q. M.; Liu, W. T.; Liu, W. F.; Sheng, Z. J.; Zheng, X.; Zhang, K.; Du, Z. Y.; Zhao, S. Q.; Wang, S. H. Bioorg. Med. Chem. Lett. 2016, 26, 5334.
[45] Marin, L.; Guillot, R.; Gandon, V.; Schulz, E.; Lebœuf, D. Org. Chem. Front. 2018, 5, 640.

[46] Shen, X.; Xia, J.; Liang, P.; Ma, X.; Jiao, W.; Shao, H. Org. Biomol. Chem. 2015, 13, 10865.

[47] Adhikary, N. D.; Kwon, S.; Chung, W. J.; Koo, S. J. Org. Chem. 2015, 80, 7693.

[48] Bharathiraja, G.; Sengoden, M.; Kannan, M.; Punniyamurthy, T. Org. Biomol. Chem. 2015, 13, 2786.

[49] Shu, C.; Wang, Y. H.; Shen, C. H.; Ruan, P. P.; Lu, X.; Ye, L. W. Org. Lett. 2016, 18, 3254.

[50] Hsu, Y. C.; Hsieh, S. A.; Li, P. H.; Liu, R. S. Chem. Commun. 2018, $54,2114$.

[51] Kardile, R. D.; Kale, B. S.; Sharma, P.; Liu, R. S. Org. Lett. 2018, $20,3806$.

[52] Hsieh, H. C.; Tan, K. C.; Raj, A. S. K.; Liu, R. S. Chem. Commun. 2019, 55, 1979.

[53] Kim, D. S.; Seo, Y. S.; Jun, C. H. Org. Lett. 2015, 17, 3842.

[54] Sakai, N.; Hori, H.; Ogiwara, Y. Eur. J. Org. Chem. 2015, 1905.

[55] Sakai, N.; Suzuki, H.; Hori, H.; Ogiwara, Y. Tetrahedron Lett. 2017, 58,63 .

[56] Li, M. B.; Grape, E. S.; Bäckvall, J. E. ACS Catal. 2019, 9, 5184.

[57] Firoozi, N.; Torres, G. M.; Arndtsen, B. A. J. Org. Chem. 2016, 81, 11145.

[58] Cheng, B. Y.; Wang, Y. N.; Li, T. R.; Lu, L. Q.; Xiao, W. J. J. Org. Chem. 2017, 82, 12134.

[59] Sahani, R. L.; Liu, R. S. Angew. Chem., Int. Ed. 2017, 56, 1026.

[60] Hu, W.; Yu, J. T.; Ye, D.; Zhou, Z.; Sun, S.; Cheng, J. J. Org. Chem. 2016, 81, 9389.

[61] Siddiki, S. M. A. H.; Touchy, A. S.; Chaudhari, C.; Kon, K.; Toyao, T.; Shimizu, K.-I. Org. Biomol. Chem. 2016, 3, 846.

[62] Kallmeier, F.; Dudziec, B.; Irrgang, T.; Kempe, R. Angew. Chem., Int. Ed. 2017, 56, 7261.

[63] Chai, H.; Wang, L.; Liu, T.; Yu, Z. Organometallics 2017, 36, 4936.

[64] Midya, S. P.; Landge, V. G.; Sahoo, M. K.; Rana, J.; Balaraman, E. Chem. Commun. 2017, 54, 90.

[65] Li, X.; Chen, M.; Xie, X.; Sun, N.; Li, S.; Liu, Y. Org. Lett. 2015, 17, 2984.

[66] Ni, C.; Wang, M.; Tong, X. Org. Lett. 2016, 18, 2240.

[67] Stuart, D. R.; Alsabeh, P.; Kuhn, M.; Fagnou, K. J. Am. Chem. Soc. 2010, 132, 18326.

[68] Rakshit, S.; Patureau, F. W.; Glorius, F. J. Am. Chem. Soc. 2010, 132,9585

[69] Yoshida, M.; Sugimura, C. Tetrahedron Lett. 2013, 54, 2082.

[70] Li, Q.; Hou, C.-J.; Hui, Y.-Z.; Liu, Y.-J.; Yang, R.-F.; Hu, X.-P. RSC Adv. 2015, 5, 85879 .

[71] Zhang, X. Y.; Yang, Z. W.; Chen, Z.; Wang, J.; Yang, D. L.; Shen, Z.; Hu, L. L.; Xie, J. W.; Zhang, J.; Cui, H. L. J. Org. Chem. 2016, $81,1778$.

[72] Zhou, N.; Li, Z.; Xie, Z. Org. Chem. Front. 2015, 2, 1521.

[73] Yu, W.; Zhang, W.; Liu, Y.; Zhou, Y.; Liu, Z.; Zhang, Y. RSC Adv. 2016, 6, 24768.

[74] Lade, D. M.; Pawar, A. B. Org. Chem. Front. 2016, 3, 836.

[75] Wang, Y.; Jiang, C. M.; Li, H. L.; He, F. S.; Luo, X.; Deng, W. P. J. Org. Chem. 2016, $81,8653$.

[76] Balachandra, B.; Shanmugam, S.; Muneeswaran, T.; Ramakritinan, M. $R S C A d v$. 2015, 5, 64781 .

[77] Weng, J.; Chen, Y.; Yue, B.; Xu, M.; Jin, H. Eur. J. Org. Chem. 2015, 3164.

[78] Nizami, T. A.; Hua, R. Tetrahedron 2017, 73, 6080.

[79] Chachignon, H.; Scalacci, N.; Petricci, E.; Castagnolo, D. J. Org. Chem. 2015, 80, 5287.

[80] Mou, X. Q.; Xu, Z. L.; Xu, L.; Wang, S. H.; Zhang, B. H.; Zhang, D.; Wang, J.; Liu, W. T.; Bao, W. Org. Lett. 2016, 18, 4032.

[81] Yang, T.; Wang, K.-H.; Huang, D.; Li, P.; Deng, Z.; Su, Y.; Hu, Y.; Tetrahedron 2019, 75, 2291.

[82] Qi, X.; Xiang, H.; Yang, Y.; Yang, C. RSC Adv. 2015, 5, 98549.

[83] Wang, Z. P.; He, Y.; Shao, P. L. Org. Biomol. Chem. 2018, 16, 5422.

[84] George, J.; Kim, H. Y.; Oh, K. Org. Lett. 2017, 19, 628. 
[85] Lu, K.; Ding, F.; Qin, L.; Jia, X.; Xu, C.; Zhao, X.; Yao, Q.; Yu, P. Chem.-Asian J. 2016, 11, 2121.

[86] Liao, J. Y.; Shao, P. L.; Zhao, Y. J. Am. Chem. Soc. 2015, 137, 628.

[87] Fang, G.; Liu, J.; Fu, J.; Liu, Q.; Bi, X. Org. Lett. 2017, 19, 1346.

[88] Liao, J. Y.; Yap, W. J.; Wu, J.; Wong, M. W.; Zhao, Y. Chem. Commun. 2017, 53, 9067.

[89] Hu, Z.; Yuan, H.; Men, Y.; Liu, Q.; Zhang, J.; Xu, X. Angew. Chem., Int. Ed. 2016, 55, 7077.

[90] Li, F.; Hu, P.; Sun, M.; Li, C.; Jia, X.; Li, J. Chem. Commun. 2018, $54,6412$.

[91] Zhou, A. H.; He, Q.; Shu, C.; Yu, Y. F.; Liu, S.; Zhao, T.; Zhang, W.; Lu, X.; Ye, L. W. Chem. Sci. 2015, 6, 1265.

[92] Xiao, X. Y.; Zhou, A. H.; Shu, C.; Pan, F.; Li, T.; Ye, L. W. Chem.Asian J. 2015, 10, 1854.

[93] Galenko, E. E.; Tomashenko, O. A.; Khlebnikov, A. F.; Novikov, M. S. Org. Biomol. Chem. 2015, 13, 9825.

[94] Pusch, S.; Kowalczyk, D.; Opatz, T. J. Org. Chem. 2016, 81, 4170.

[95] Xiao, Z. F.; Ding, T. H.; Mao, S. W.; Shah, Z.; Ning, X. S.; Kang, Y. B. Org. Lett. 2016, 18, 5672.

[96] Kakaawla, T. K. K.; Harrity, J. P. A. Org. Lett. 2018, 20, 201.

[97] Zhao, Y. Z.; Yang, H. B.; Tang, X. Y.; Shi, M. Chemistry 2015, 21, 3562.

[98] Wang, Y.; Lei, X.; Tang, Y. Chem. Commun. 2015, 51, 4507.

[99] Donthiri, R. R.; Samanta, S.; Adimurthy, S. Org. Biomol. Chem. 2015, 13, 10113.

[100] Pawar, S. K.; Sahani, R. L.; Liu, R. S. Chemistry 2015, 21, 10843.

[101] Wu, Y.; Zhu, L.; Yu, Y.; Luo, X.; Huang, X. J. Org. Chem. 2015, 80, 11407.

[102] Zhao, M. N.; Ren, Z. H.; Yang, D. S.; Guan, Z. H. Org. Lett. 2018, $20,1287$.

[103] Huang, Z.; Gong, Y. RSC Adv. 2016, 6, 22357.

[104] Su, Z.; Gu, W.; Qian, S.; Xue, S.; Wang, C. Eur. J. Org. Chem. 2018, 1019.

[105] Tan, W. W.; Yoshikai, N. Chem. Sci. 2015, 6, 6448.

[106] Cruz, F. N.; López, J.; Jiménez-Halla, J. O.; Flores-Álamo, M.; Tamaríz, J.; Delgado, F.; Vázquez, M. A. Org. Biomol. Chem. 2015, 13,11753 .

[107] Kuruba, B. K.; Vasanthkumar, S.; Emmanuvel, L. Tetrahedron
2017, 73, 3093.

[108] Mohammadi, B.; Khorrami, B. R.; Ghorbani, M.; Dusek, M. Tetrahedron 2017, 73, 7291.

[109] Tian, Z.; Xu, J.; Liu, B.; Tan, Q.; Xu, B. Org. Lett. 2018, 20, 2603.

[110] Sha, Q.; Arman, H.; Doyle, M. P. Org. Lett. 2015, 17, 3876.

[111] Wu, X.; Li, K.; Wang, S.; Liu, C.; Lei, A. Org. Lett. 2016, 18, 56.

[112] Gao, X.; Wang, P.; Wang, Q.; Chen, J.; Lei, A. Green Chem. 2019, $21,4941$.

[113] Li, Q.; Fan, A.; Lu, Z.; Cui, Y.; Lin, W.; Jia, Y. Org. Lett. 2010, 12, 4066.

[114] Huang, H.; Tang, L.; Cai, J.; Deng, G.-J. RSC Adv. 2016, 6, 7011.

[115] Dang, T. T.; Seayad, A. M. Chem.-Asian J. 2017, 12, 2383.

[116] Borghs, J. C.; Azofra, L. M.; Biberger, T.; Linnenberg, O.; Cavallo, L.; Rueping, M.; El-Sepelgy, O. ChemSusChem. 2019, 12, 3083.

[117] Malone, J. A.; Toussel, C. E.; Fronczek, F. R.; Kartika, R. Org. Lett. 2019, 21, 3610.

[118] Xu, C.; Han, Y.; Chen, S.; Xu, D.; Zhang, B.; Shan, Z.; Du, S.; Xu, L.; Gong, P. Tetrahedron Lett. 2018, 59, 260.

[119] Gilbert, Z. W.; Hue, R. J.; Tonks, I. A. Nat. Chem. 2016, 8, 63

[120] Chiu, H. C.; See, X. Y.; Tonks, I. A. ACS Catal. 2019, 9, 216.

[121] Pearce, A. J.; See, X. Y.; Tonks, I. A. Chem. Commun. 2018, 54, 6891.

[122] Zhang, X.; Xu, X.; Chen, G.; Yi, W. Org. Lett. 2016, 18, 4864.

[123] Zeng, J.-C.; Xu, H.; Huang, R.-L.; Yu, F.; Zhang, Z. Tetrahedron Lett. 2018, 59, 1576.

[124] Zhao, D.; Zhu, Y.; Guo, S.; Chen, W.; Zhang, G.; Yu, Y. Tetrahedron 2017, 73, 2872.

[125] Liu, X.; Nie, Z.; Shao, J.; Chen, W.; Yu, Y. New J. Chem. 2018, 42, 2368.

[126] Goyal, S.; Patel, J. K.; Gangar, M.; Kumar, K.; Nair, V. A. RSC Adv. 2015, 5, 3187.

[127] Liu, Y.; Yi, X.; Luo, X.; Xi, C. J. Org. Chem. 2017, 82, 11391.

[128] Peng, J.; Gao, Y.; Hu, W.; Gao, Y.; Hu, M.; Wu, W.; Ren, Y.; Jiang, H. Org. Lett. 2016, 18, 5924.

[129] Wang, G. Q.; Zhu, J. Org. Lett. 2017, 19, 270.

[130] Peng, J.; Gao, Y.; Zhu, C.; Liu, B.; Gao, Y.; Hu, M.; Wu, W.; Jiang, H. J. Org. Chem. 2017, 82, 3581. 